\title{
Infrared Studies of Association in Eleven Alcohols
}

\author{
Francis A. Smith and E. Carroll Creitz
}

\begin{abstract}
This work provides information to facilitate the interpretation of the structures of carbohydrates in terms of their infrared absorption spectra and additional knowledge of the properties of alcohols as associated solvents. The spectra of methanol, 1-dodecanol, 2-methyl-2-propanol ( $t$-butyl alcohol), 3-pentanol, 3-methyl-3-pentanol, 2,2,4-trimethyl-3pentanol, 2,4-dimethyl-3-ethyl-3-pentanol, 2,2,4-trimethyl-3-ethyl-3-pentanol, 2,2,4-trimethyl-3-isopropyl-3-pentanol, 2,2,4,4-tetramethyl-3- $n$-propyl-3-pentanol, and 2,2,4,4-tetramethyl-3-isopropyl-3-pentanol have been studied.

Some of the effects of dilution in nonpolar solvents, and of steric hindrance by branching, on their intermolecular association through the formation of hydrogen bridges have been determined.

Evidence is presented for the existence of a single-bridge type of dimer.

The assignment of the band at 2.86 microns to dimer has been given strong support.

An isobestic point, at which the molar absorbancy index (28.6) is independent of the degree of dissociation, was found at 8.82 microns in the spectrum of 3-pentanol. Others not so well marked appear in the spectra of some of the other alcohols. Such points facilitate the quantitative determination of such alcohols in favorable circumstances.

The absorptions of the monomer and the dimer, separately, appear to obey Beer's law.

Both the monomer and the single-bridge dimer appear to contribute to the free hydroxyl absorption; their relative contributions depend upon the concentration of the solution.
\end{abstract}

\section{Introduction}

The interpretation of the infrared spectra of carbohydrates and other hydroxyl-bearing compounds in terms of molecular structure is complicated by the intra- and intermolecular association of such compounds through the formation of hydrogen bridges $[1,2] .{ }^{1}$ Many workers have investigated these association phenomena and their effects on the infrared spectrum by means of progressive dilution in solvents [3 to 7]. As the average intermolecular distance increases with dilution, a progressively larger number of bridges are broken, with a corresponding effect upon the spectrum.

A solvent suitable for the study of association between molecules of the solute should (a) dissolve the solute in appreciable quantities; (b) be free from absorption bands of its own in the region to be studied; (c) show no association with the solute. Solvents in which carbohydrates, such as cellulose, are sufficiently soluble usually contain $\mathrm{O}$ or $\mathrm{N}$ (to which the solute could form hydrogen bridges) and have relatively complex spectra. Consequently, it has not been possible to study such carbohydrates by this method directly. The same situation exists in the case of sugars, although their solubility in otherwise suitable solvents may be increased slightly by partial acetylation. Many monohydric alcohols, however, are sufficiently soluble in such solvents as carbon tetrachloride and carbon disulfide, which have been shown to be otherwise suitable.

Several possible types of aggregation that may result from the association of alcohols are illustrated diagrammatically in figure 1.

The free fundamental valence stretching vibration of the hydrogen-oxygen bond has been shown to result in a sharp absorption band at approximately $2.75 \mu\left(3,636 \mathrm{~cm}^{-1}\right)$, which is little affected by the

Figures in brackets indicate the literature references at the end of this paper nature of the rest of the molecule to which the hydroxyl is attached. The free hydroxyl of monomer, unaffected by other molecules, may be expected to absorb at a slightly shorter wavelength than the free hydroxyl of single-bridged dimer or the terminal free hydroxyl of polymer. In the latter cases the bridge to oxygen formed by the hydrogen of another molecule absorbs part of the available energy, weakening the free $\mathrm{O}-\mathrm{H}$ bond and resulting in absorption at a slightly longer wavelength. A band at approximately $2.86 \mu\left(3,497 \mathrm{~cm}^{-1}\right)$ has been ascribed $[3,4]$ to the fundamental stretching vibration of the $\mathrm{O}-\mathrm{H}$ in dimer in which the hydrogen participates in a bridge between its own oxygen and the oxygen of another molecule. In such cases, represented in figure 1 by the bridged $\mathrm{O}-\mathrm{H} \cdot \cdots \mathrm{O}$ of the single-bridge dimer and the terminal $\mathrm{O}-\mathrm{H}$. . O of the polymer, the $\mathrm{O}-\mathrm{H}$ bond is weakened much more than was the case in the change from monomer to the free hydroxyl of dimer. When several molecules are linked together as indicated for polymer in figure 1 (except in the case of the formation of a closed ring), there will be a free hydroxyl group at one end and a bridged hydroxyl group at the other, like those just discussed above. All the internal $\mathrm{O}-\mathrm{H}$ vibrations will be of the type in which both oxygen and hydrogen, instead of oxygen or hydrogen alone, participate in bridges to other molecules. In this case the $\mathrm{O}-\mathrm{H}$ bond is weakened even more than in the other cases, and the still lower frequency of the fundamental stretching vibration results in an absorption band centering near $3 \mu \quad\left(3,333 \quad \mathrm{~cm}^{-1}\right)$. The skeletal vibrations of long chains of such nature could result in a relatively continuous statistical variation in the lengths, strengths, and frequencies of vibration of the $\mathrm{O}-\mathrm{H}$ bonds of the intermediate bridges and so account for the breadth of the absorption band and the lack of indication of discrete fine structure even at high resolution. The situation in the case of the 
double-bridged type of dimer represented in figure 1 differs from that of the polymer $(. . \mathrm{O}-\mathrm{H} \cdots)_{n}$ in several respects. The $\mathrm{O}-\mathrm{H} \ldots \mathrm{O}$ angle in the dimer is necessarily much smaller, and consequently the bridge can exert less effect upon the $\mathrm{O}-\mathrm{H}$ stretching frequency than would be the case if the angle were nearly straight. But both hydrogen and oxygen of both molecules participate in bridges. The combined result of both effects should place the absorption of the $\mathrm{O}-\mathrm{H}$ bond of double-bridged dimer at a wavelength somewhere between that of free hydroxyl and that of polymer. The quadrangle formed by the doubly bridged pair of hydroxyl groups should be planar, and the in-plane bending vibrations of the $\mathrm{O}-\mathrm{H}$ bond should be much more affected by the bridges than the out-of-plane bending with a marked difference between the frequencies of the in-plane and out-of-plane vibrations. Available spectra of the liquids, obtained with rock salt prisms, indicate on this basis that, undiluted, the shorter $n$-1-alkanols are almost completely associated. With the higher resolution obtained with the lithium fluoride prism, and at sufficiently slow rates of scanning, some indication of free hydroxyl is sometimes found. Indicatons of any "dimer" that may be present are often obscured by the broad polymer band.

In this work, as a means of improving the basis for the interpretation of the spectra of alcohols of more complex structure, several of the simpler alcohols have been used to study the following:

The effects of progressive dilution in carbon tetrachloride on the relative intensities of the fundamental stretching bands at about $2.75,2.86$, and $3 \mu$, and of the first harmonic bands from 1.2 to $1.7 \mu$. 1-Dodecanol, 2-methyl-2-propanol ( $t$-butyl alcohol), 3-pentanol, and 2,4-dimethyl-3-ethyl-3-pentanol were used for this purpose.

The effects of dilution on the intensities of the bands of 3-pentanol from 6.65 to $9.7 \mu$, and of methanol from 2 to $12 \mu$, in order to identify bands connected with the $\mathrm{O}-\mathrm{H}$ bending vibration.

The effects on association of the steric hindrance produced by branching. The following series of eight increasingly branched alkyl derivatives of 3-pentanol, undiluted, were used in this study: 3-pentanol, 3-methyl-3-pentanol, 2,2,4-trimethyl-3pentanol, 2,4-dimethyl-3-ethyl-3-pentanol, 2,2,4-trimethyl-3-ethyl-3-pentanol, 2,2,4-trimethyl-3-isopropyl-3-pentanol, 2,2,4,4-tetramethyl-3- $n$-propyl-3pentanol, and 2,2,4,4-tetramethyl-3-isopropyl-3pentanol.

\section{Materials}

The methanol used was part of a sample of duPont GRX methanol, a catalytic product, prepared as a raw material for the catalytic production of hydrogen by a process in which trace impurities except water were known to poison the catalyst. The portion used was dried by standing over activated silica gel.

The 1-dodecanol, obtained from John D. Hoffman of Princeton Univ., had been purified by crystalliza- tion from dry ether followed by five fractional distillations at $1 \mathrm{~mm}$. Freezing point, $23.5^{\circ} \mathrm{C}$, [8].

The 2-methyl-2-propanol ( $t$-butyl alcohol) obtained from Frank L. Howard, Engine Fuels Section, was recrystallized by freezing.

The 3-pentanol and its seven alkyl derivatives [9] were obtained from Howard, who supplied the following data: All the carbinols except 2,2,4,4-tetramethyl-3- $n$-propyl-3-pentanol were center fractions from the distillation of large quantities through columns with an efficiency of about 30 theoretical plates.

The 3-pentanol was prepared by the fractionation of commercial mixed secondary alcohols in a column of about 110 theoretical plates.

The 3-methyl-3-pentanol was prepared from ethylmagnesium chloride plus ethyl acetate.

The 2,4-dimethyl-3-ethyl-3-pentanol was prepared from ethyl-magnesium chloride plus diisopropyl ketone. Freezing point, $-16.0^{\circ} \mathrm{C}$; boiling point, $177.9^{\circ} \mathrm{C} ; n,{ }_{D}^{20} 1.4439 ; D_{4}^{20}, 0.8588$.

The 2,2,4,4-tetramethyl-3-isopropyl-3-pentanol was prepared from $t$-butyl chloride plus ethyl isobutyrate. Boiling point, $234.0^{\circ} \mathrm{C} ; n_{D}^{20}, 1.4646 ; D_{4}^{20}, 0.8889$; possible impurity, pentamethyl acetone.

The 2,2,4-trimethyl-3-isopropyl-3-pentanol was prepared from methyl trimethyl acetate plus isopropyl chloride. Freezing point, $-18.3^{\circ} \mathrm{C}$; boiling point, $215.4^{\circ} \mathrm{C} ; n_{D}^{20}, 1.4574 ; D_{4}^{20}, 0.8758$; possible impurity, pentamethyl acetone.

The 2,2,4-trimethyl-3-pentanol was a byproduct obtained during the preparation of $2,2,4$ trimethyl 3 -isopropyl-3-pentanol and was formed by reduction of pentamethyl acetone. Freezing point, $-11.3^{\circ} \mathrm{C}$; boiling point $151.3^{\circ} \mathrm{C} ; n_{D}^{20}, 1.4287 ; D_{4}^{20}, 0.8322$.

The 2,2,4-trimethyl-3-ethyl-3-pentanol was prepared from ethyl bromide and pentamethyl acetone. Boiling point, 93 to $97^{\circ} \mathrm{C}$ at $35 \mathrm{~mm} ; \bar{n}_{D}^{20}, 1.4479$; $D_{4}^{20}, 0.862$; purest of the group, no significant quantity of any known impurity.

The 2,2,4,4-tetramethyl-3- $n$-propyl-3-pentanol was prepared from hexamethyl acetone and $n$-propyl chloride, also from methyl- $n$-butyrate and $t$-butyl chloride. Boiling point, $117^{\circ} \mathrm{C}$ at $22 \mathrm{~mm} ; n_{D}^{20}$, $1.4563 ; D_{4}^{20}, 0.8595$.

Carbon tetrachloride was several center fractions from a distillation through a Widmer column. $n_{D}^{20}, 1.4574$ to 1.4577 .

Several of the spectra of the alkyl derivatives of 3-pentanol showed an absorption band at $5.82 \mu$ $\left(1,718 \mathrm{~cm}^{-1}\right)$, in the range where carbonyl absorptions might be expected. Ketones and esters were possible impurities in some of the alcohols, and the possible contribution of any of the alcohols to the absorption at this wavelength was unknown. The 2,2,4-trimethyl-3-ethyl-3-pentanol was stated to be the purest of this group of alcohols, and its spectrum showed no marked absorption greater than background at $5.82 \mu$. Consequently, its absorbance index at this wavelength was used as a background value above which to estimate spectrometrically the possible upper limit of carbonyl group impurities in the others. The result is shown in the following tabulation in mole percent. 
0. 4

. 1

2. 2

2. 3

3. 4

. 2
This estimated upper limit would, of course, be diminished to the extent to which the alcohol is found to contribute to the absorption at this wavelength in any given instance.

\section{General Experimental Procedure}

The spectra were recorded with a Perkin-Elmer spectrometer model $12-\mathrm{B}$, using a lithium fluoride prism. The spectra of the solutions of 3-pentanol and methanol were also recorded by using a rocksalt prism, as were those of the series of undiluted alkyl derivatives of 3-pentanol. The characteristics of the spectrometer and the method of operation have been described previously [10].

The temperature of the air at the spectrometer was approximately $25.2^{\circ} \mathrm{C}$ at all times, and the temperature of the samples during measurement probably did not differ greatly from this.

The cells used were constructed with rock-salt windows and lead or tin spacers cemented with amalgam as described previously [11]. The thickness of the cells was measured by the interference method of Smith and Miller [12]. The spectra of solutions were corrected for cell and solvent losses by using as a blank a cell of nearly identical thickness filled with solvent, and for scattered energy by the use of shutters of glass and lithium flouride. Cell losses were compensated in the case of the undiluted alcohols by the use of a window of double thickness as a blank.

By using the densities of the alcohols and of the solvent, and assuming no volume change on mixing, molar solutions were prepared by weight, the concentrations being adjusted when possible (as dilution progressed) to correspond to successively increasing thicknesses of the fixed cells, so that the weight of a given solute in the absorbing path would remain approximately the same at all concentrations. If possible, the spectrum of each solution was recorded on the day it was prepared, to avoid the preferential loss of the lighter alcohols by evaporation noted by Saier and Coggeshall [13], or of solvent in other cases.

Change of concentration during the process of filling the cells was minimized by the use of the device shown in figure 2 . A $30-\mathrm{ml}$ bottle with a standard taper cap, containing the solution, was supported on a platform. The cap was replaced with a dispensing fitting having a short vertical outlet surmounted by a small male standard taper. The fixed absorption cell was supported above it in "ways," or positioning guide slots, like those on the spectrometer housing. The lower cell fitting was provided with a nut containing a tapered teflon packing, which, when lowered upon the small standard taper of the dispenser, provided a reasonably tight connection. The upper cell fitting was provided with another small male standard taper, made tight with a nut and teflon packing, to serve as a sight-glass and to indicate any loss of solution. Air dried over silica gel was forced into the bottle over the solution. When the solution rose into the cell and sight-glass the air was turned off, the upper standard taper was capped, the cell separated from the dispenser, the connecting nut replaced by a teflon. sealed cap nut, and the dispenser capped.

\section{Treatment of the Data}

Terminology and symbols conform to the usage outlined in NBS Letter Circular LC857.

For undiluted alcohols, $T$, (transmittance $)=I / I_{0}$, where $I_{0}$ is the intensity of radiation incident on the sample, and $I$ is the intensity of that transmitted. "Transmittance in percent" $=100$ T. $a_{M}$ ("molar absorbance index" $)=1 / b c \log _{10} 1 / T$, where $b$ is the thickness of the cell in centimeters, and $c$ is the concentration or number of moles per liter.

For solutions, $T=I_{\text {soln }} / I_{\text {solv }}$ and molar absorbancy index differs from molar absorbance index also in that the concentration $c$ is expressed in moles per liter of solution.

Assuming the accuracy of the values of transmittance, concentration, and cell thickness, as well as obedience to Beer's law, an absorption band resulting from $\mathrm{C}-\mathrm{H}$ should yield a value of molar absorbency index that is independent of concentration. In those cases in which such a band was present adjacent to the spectral range of interest, it was used as an internal standard by which to evaluate a factor, constant for any one solution, with which to adjust the values of molar absorbency index of one or more solutions in a group to give a constant value for the "standard" band. Such deviations from a constant value reflect probable uncertainties in the numerical values, as well as possible deviations from Beer's law. The application of such a correction bas resulted in a general improvement of the relative numerical values of the curves of a group, as evidenced by its effect upon several isosbestic points, some of which are reasonably good after the correction.

The data have all been plotted by using a linear wavelength scale reading from left to right, with a corresponding scale in wave numbers.

Certain sections of some curves have been delineated by small dots to indicate that unusual uncertainties exist in the photometric data because of strong bands in the background or solvent, or of the $\mathrm{F}-\mathrm{H}$ absorption by the lithium fluoride prism.

\section{Results}

\section{Effect of Dilution on the O-H Stretching Vibrations}

The spectral changes in the vicinity of the $\mathrm{O}-\mathrm{H}$ fundamental stretching vibration that accompany the dissociation of 1-dodecanol, 2-methyl-2-propanol, 
3-pentanol, and 2,4-dimethyl-3-ethyl-3-pentanol as each was progressively diluted in carbon tetrachloride are shown in figures 3 to 6 , respectively, in which molar absorbency index is plotted aginst wavelength. Letters on the curves correspond with the concentrations and cell thickness indicated in the captions. The number 0 indicates undiluted alcohol.

The coexistence of free hydroxyl, dimer and polymer states of aggregation in 1-dodecanol, 2-methyl-2-propanol and 3-pentanol, is indicated in figures 3,4 , and 5 , respectively, by the presence in each of bands at about $2.76,2.86$, and $3.0 \mu$, respectively.

Undiluted 3-pentanol (curve 0 of fig. 5) shows a little free hydroxyl but any evidence of dimer is unobservable. There is some evidence of dimer in the spectra of all the solutions in all the figures.

It will be noted that there is no progressive shift of the wavelength of the bands connected with the several states of aggregation. Each band is characteristic of a given state of aggregation, and the changes in the relative intensities of the three bands reflect the relative population of the three states of aggregation in the solutions.

Although the molar concentrations represented by curves a in figures 3 and 4 are approximtaely the same (2.914 and 2.416 , respectively), the population of free hydroxyl in 1-dodecanol is much less than in 2-methyl-2-propanol. It was necessary to reduce the molar concentration of the former to 0.651 in order to attain the same degree of dissociation, as evidenced by free hydroxyl, as was attained at 2.416 moles/liter in the latter. The less complete association of undiluted 2-methyl-2-propanol and its apparently greater tendency toward dissociation on dilution, as compared to 1-dodecanol, was attributed to the effect of the steric hindrance of the $t$-butyl groups. This led to the study of the series of progressively branched alkyl derivatives of 3-pentanol to be discussed later.

In figure 6 the spectrum of 2,4-dimethyl-3-ethyl3 -pentanol shows little or no evidence of polymer absorption. The dimer band at about $2.85 \mu$ is relatively narrow, as compared with the broad polymer bands of the other alcohols, and much stronger than its counterpart in the other three. The free hydroxyl peak of the undiluted alcohol (curve 0) is much stronger than that of the 3-pentanol (curve 0 of fig. 5) or that of the most concentrated solution of the 2-methyl-2-propanol (curve a of fig. 4).

Most significant is the indication of the doublet character of both peaks in curves 0 and a of figure 6 . The dimer peak of curve 0 has a stronger component at $2.842 \mu$ with a shoulder at a slightly longer wavelength, $2.857 \mu$. The free hydroxyl peak of curve 0 has a stronger component at $2.763 \mu$ with a shoulder at a slightly shorter wavelength, $2.757 \mu$. A similar situation exists in curve a with the relative intensities of the two components reversed. Curves b, c, d, and e, corresponding to successively more dilute solutions show the shorter wavelength component of the free hydroxyl peak.
This situation is interpreted to mean that in the undiluted alcohol most of the stretching vibration of free $\mathrm{O}-\mathrm{H}$ is that in a single-bridge type of dimer such as that proposed by Fox and Martin [3] as one possible type of hydrogen bridge (see fig. 1). Such participation of the oxygen would diminish the force constant of its bond to free hydrogen, resulting in absorption at a slightly longer wavelength. In the first solution, (curve a), most of the stretching vibration of the free $\mathrm{O}-\mathrm{H}$ results from monomer, although a portion is attributable to the free hydrogen of the single-bridge dimer. The relative proportion of monomer to single-bridge dimer increases with dilution.

The splitting of the free hydroxyl absorption was noted by Fox and Martin [14], working with benzyl alcohol, and by Coggeshall [15], working with phenols. Fox and Martin [3] presented evidence, based on equilibrium constants, against a singlebridge type of dimer, but in their later work [14] while suggesting the possibility that the band at $2.765 \mu$ results from the interaction of hydroxyl and phenyl groups, they also consider the possibility of single-bridge dimer. Coggeshall attributes the splitting in 2,6-t-amyl-4-t-butyl phenol to the presence of an impurity in which a single large group is substituted in the ortho position, and notes the disappearance of the longer wavelength component on dilution.

The two components of the dimer peak noted in figure 6 also suggest the possibility that they result from single-bridge and double-bridge dimers. Additional evidence from the free hydroxyl peaks of the series of branched alkyl derivatives of 3-pentanol will be presented in the discussion of their absorption curves.

The absorptions represented by the shoulders on several of the curves of figure 6 at $2.822 \mu$ probably represent contributions unrelated to the hydroxyl group because they appear to be unaffected by dilution.

The spectral changes in the vicinity of the first harmonic of the $\mathrm{O}-\mathrm{H}$ stretching vibration that result from the dissociation accompanying dilution of 3-pentanol in carbon tetrachloride are shown in figure 7 . The numerical values of molar absorbancy index plotted are 100 times the actual values. The band at $1.7 \mu$ was used as an internal standard as described above. In addition to the changes at $1.4 \mu$ $\left(7,143 \mathrm{~cm}^{-1}\right)$ maximum differences between curves $\mathrm{o}$ and $\mathrm{c}$ appear at about 1.50 and $1.57 \mu$, indicating bands connected with the associated molecules. Their wavelengths do not bear the same ratio to the polymer and dimer peaks of figure 5 as do the free hydroxyl peaks of the two figures, so they may not represent absorption of polymer and dimer, as such. An imperfect isosbestic point appears in the vicinity of $1.43 \mu\left(6,993 \mathrm{~cm}^{-1}\right)$ with a molar absorbancy index of about 0.1 .

\section{Effect of Dilution on $\mathrm{O}-\mathrm{H}$ Bending Vibrations}

The identification of the absorption bands connected with the $\mathrm{O}-\mathrm{H}$ bending vibrations appears to 

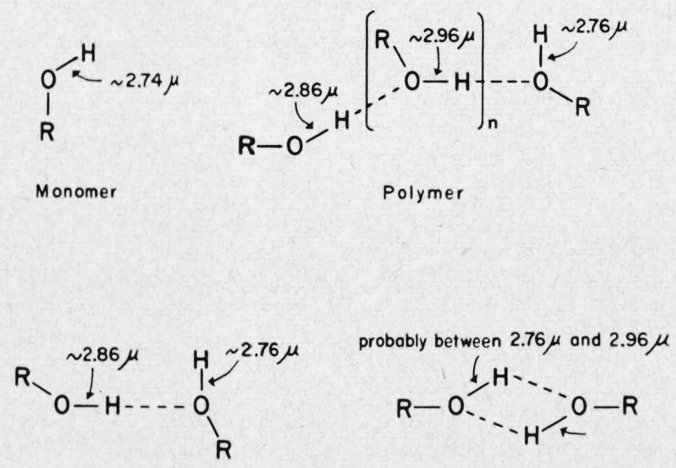

Single-bridge Dimer

Double-bridge Dimer

Figure 1. Types of aggregation in the association of alcohols.

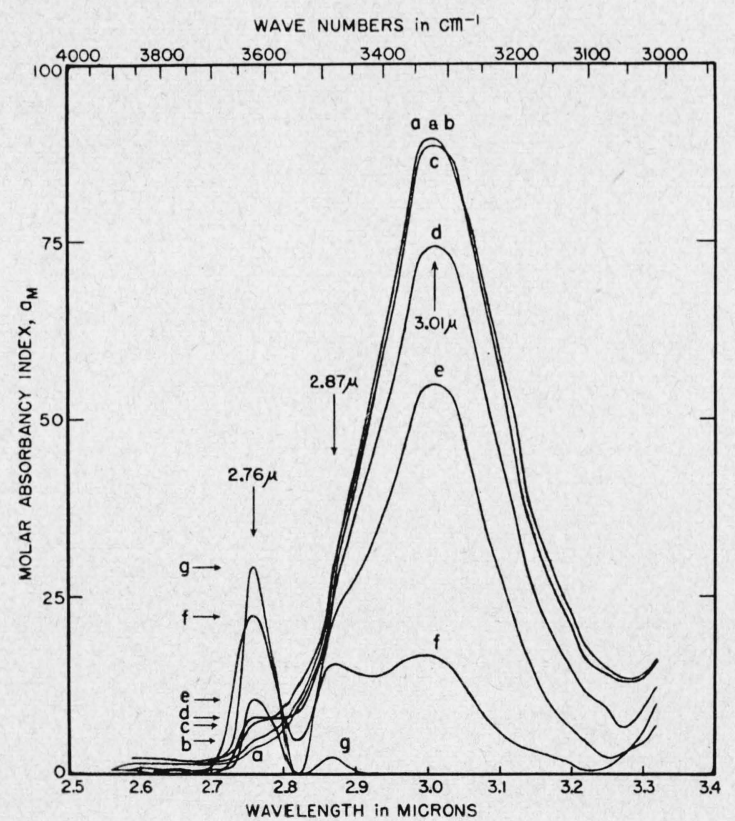

Figure 3. $\mathrm{O}-\mathrm{H}$ fundamental stretching bands of 1-dodecanol in $\mathrm{CCl}_{4}$ solution.

$\mathrm{LiF}$ prism. Concentrations in moles per liter and cell thicknesses in centimeters are, respectively: Curve (a) $2.914,0.0108$; (b) $1.889,0.0108$; (c) $1.148,0.0108$; (d) $0.651,0.0108$; (e) $0.362,0.0108$; (f) $0.100,0.0461$; (g) $0.0236,0.200$.

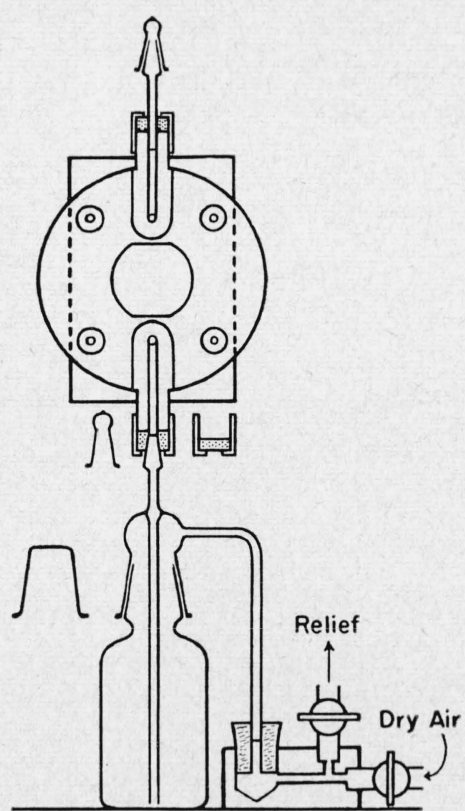

Figure 2. Dispensing device for transfer of volatile solutions from bottle to absorption cell.

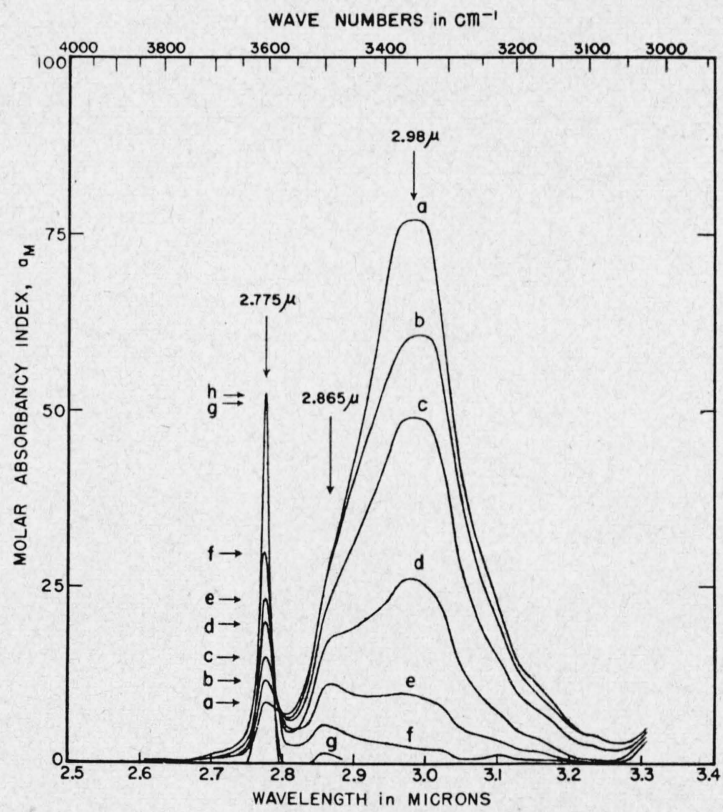

Figure 4. $\mathrm{O}-\mathrm{H}$ fundamental stretching bands of 2 -methyl-2propanol in $\mathrm{CCl}_{4}$ solution.

$\mathrm{LiF}$ prism. Concentrations in moles per liter and cell thicknesses in centimeters are, respectively: Curve (a) $2.416,0.0108$; (b) $1.308,0.0202 ;$ (c) $0.650,0.0461$; (d) $0.263,0.100 ;$ (e) $0.129,0.200$; (f) $0.065,0.200 ;$ (g) $0.0335,0.200$; (h) $0.0087,0.200$; 


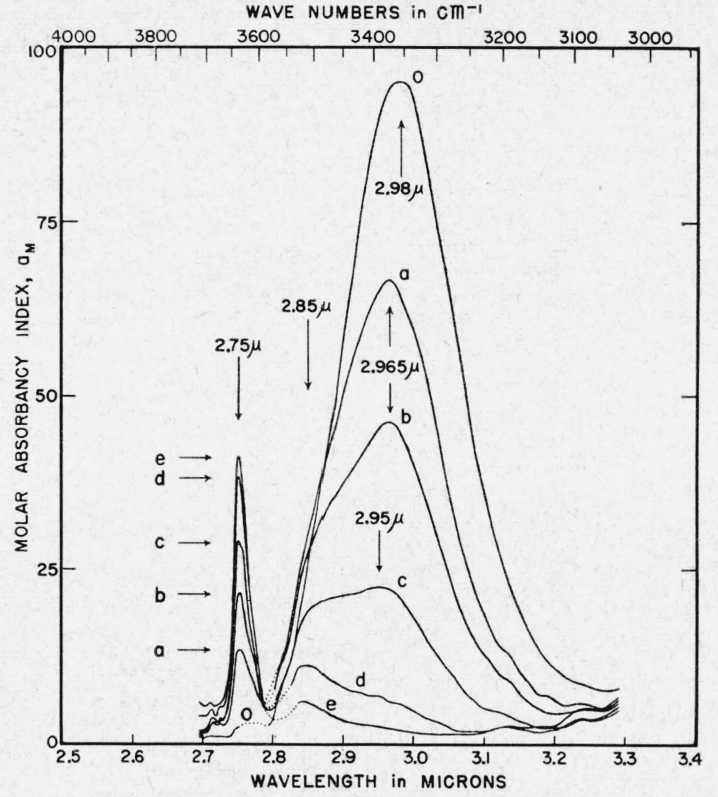

Figure 5. $\mathrm{O}-\mathrm{H}$ fundamental stretching bands of 3-pentanol in $\mathrm{CCl}_{4}$ solution.

LiF prism. Concentrations in moles per liter and cell thicknesses in centimeters are, respectively: Curve (O), undiluted, $9.245,0.0016$; (a) $1.587,0.0087$; (b) 0.7068 , 0.0190 ; (e) $0.3253,0.0427$; (d) $0.1408,0.100$; (e) $0.0568,0.269$.

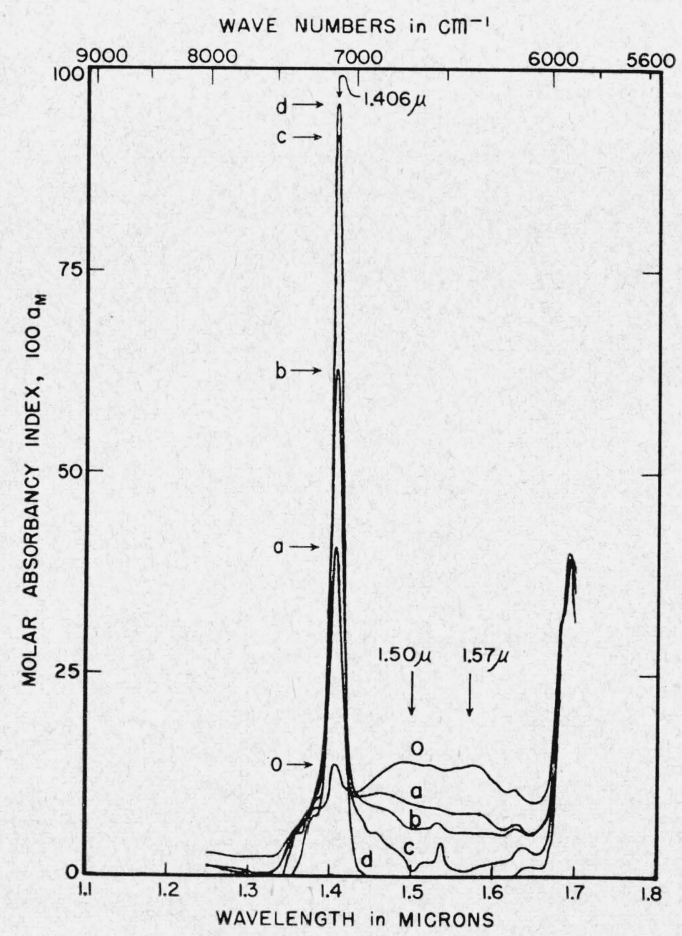

Figure 7. First harmonic of the $\mathrm{O}-\mathrm{H}$ stretching bands of 3-pentanol in $\mathrm{CCl}_{4}$ solution.

LiF prism. Concentrations in moles per liter and cell thicknesses in centimeters are, respectively: Curve (O) undiluted, $9.245,0.269$; (a) $1.587,1.196$; (b) 0.7068 , 1.196 ; (c) $0.3253,1.196$; (d) $0.1408,1.196$.

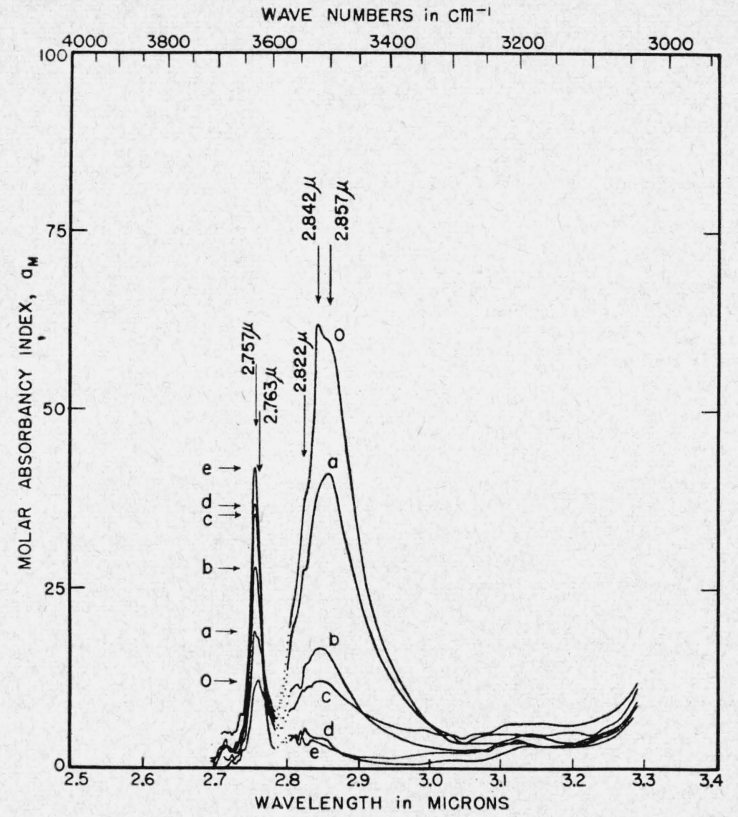

Figure 6. $\mathrm{O}-\mathrm{H}$ fundamental stretching bands of 2,4dimethyl-3-ethyl-3-pentanol in $\mathrm{CCl}_{4}$ solvtion.

LiF prism. Concentrations in moles per liter and cell thicknesses in centimeters are, respectively: Curve (O), undiluted, 5.924, 0.0015; (a) 2.849,0.0031; (b) 0.898, 0.0087 ; (c) $0.468,0.0190$; (d) $0.2010,0.0427$; (e) $0.0864,0.100$

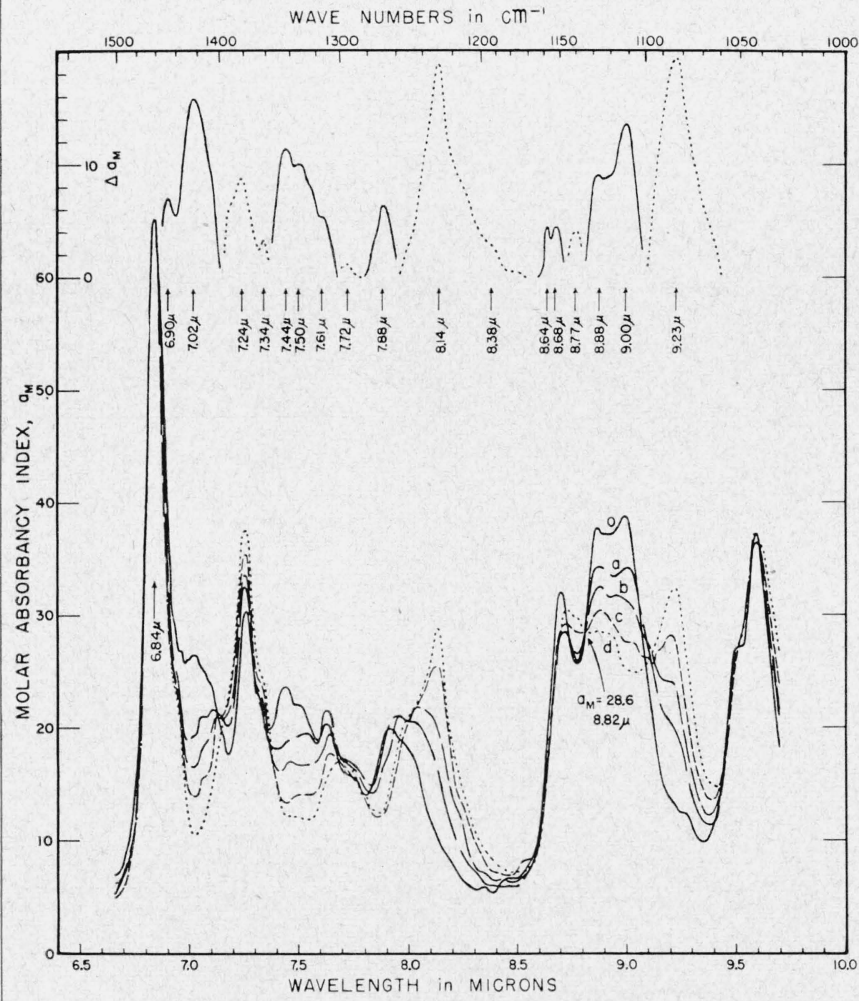

Figure 8. Bands of 3-pentanol in the $\mathrm{O}-\mathrm{H}$ bending region that change in intensity on dilution in $\mathrm{CCl}_{4}$ solution.

$\mathrm{NaCl}$ prism. Concentrations in moles per liter and cell thicknesses in centimeters are, respectively: Curve (O) undiluted, $9.25,0.0015$; (a) $1.597,0.0089$; (b) 0.7068 ,
0.0192 ; (c) $0.3253,0.0423$; (d) $0.1408,0.100$. 


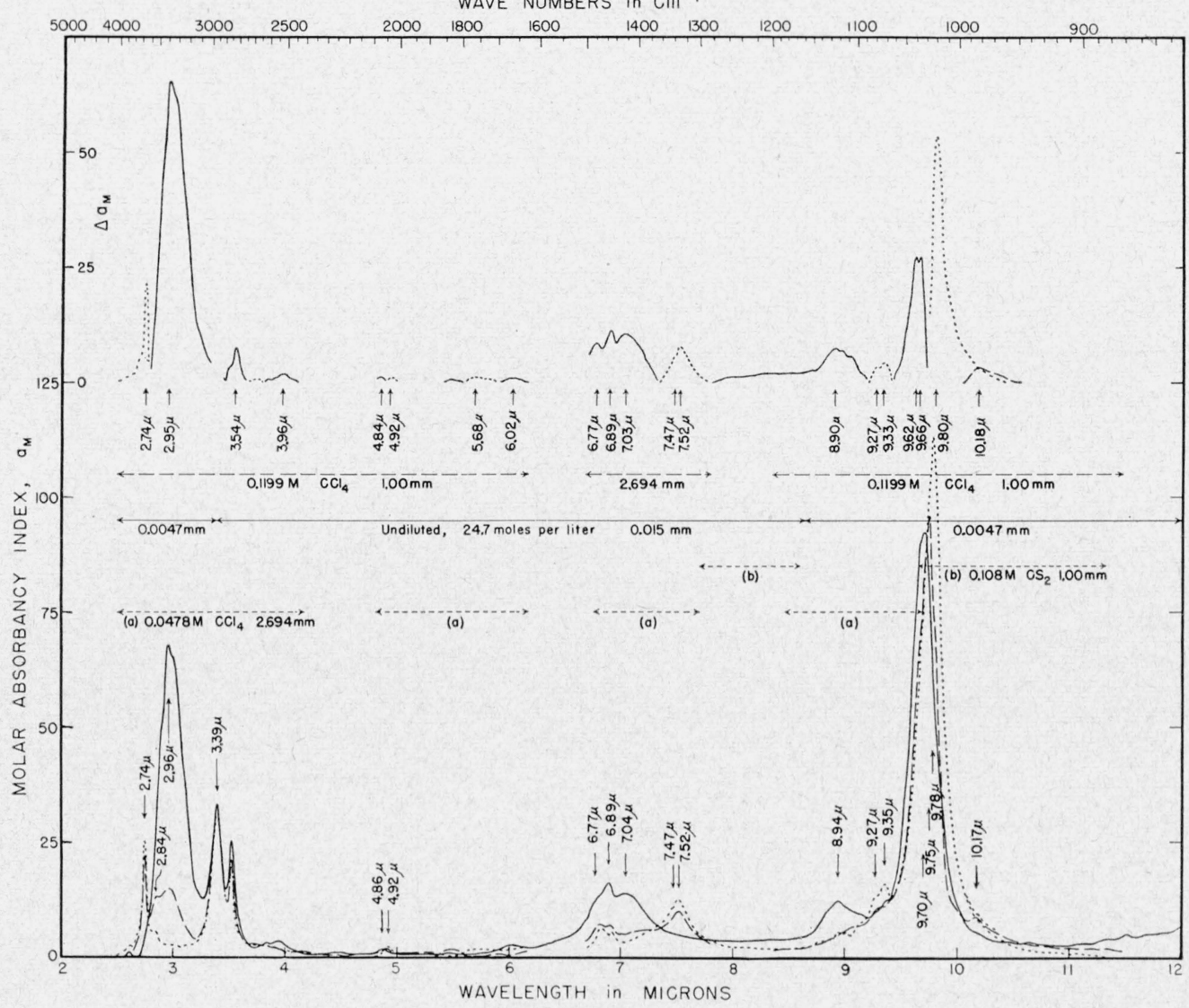

FIgURE 9. Spectrum of methanol, showing bands that change in intensity as a result of dilution in $\mathrm{CCl}_{4}$ or $\mathrm{CS}_{2}$.
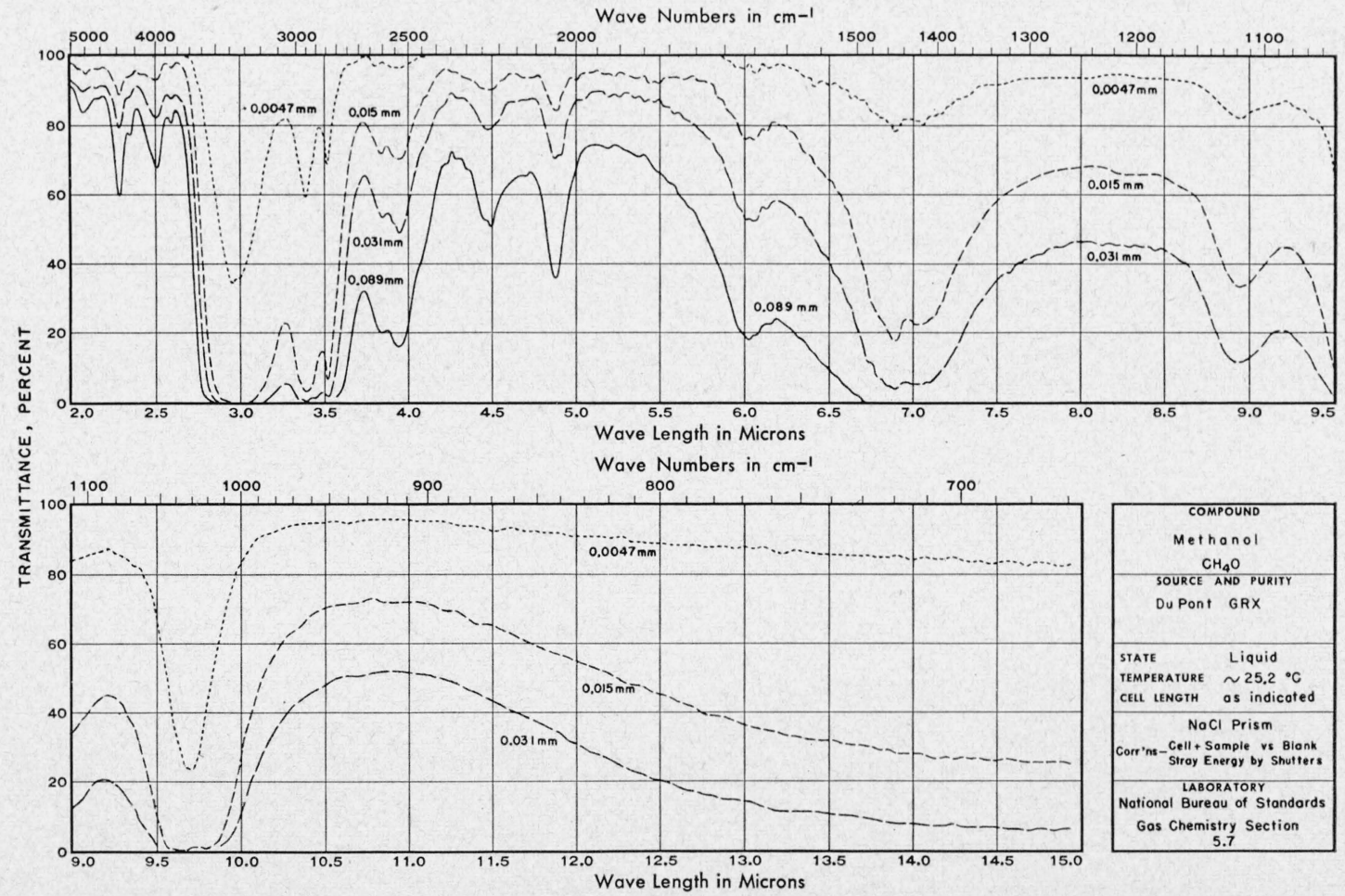

FIGURE 10. Spectrum of liquid methanol from 2 to 15 microns; $\mathrm{NaCl}$ prism. 


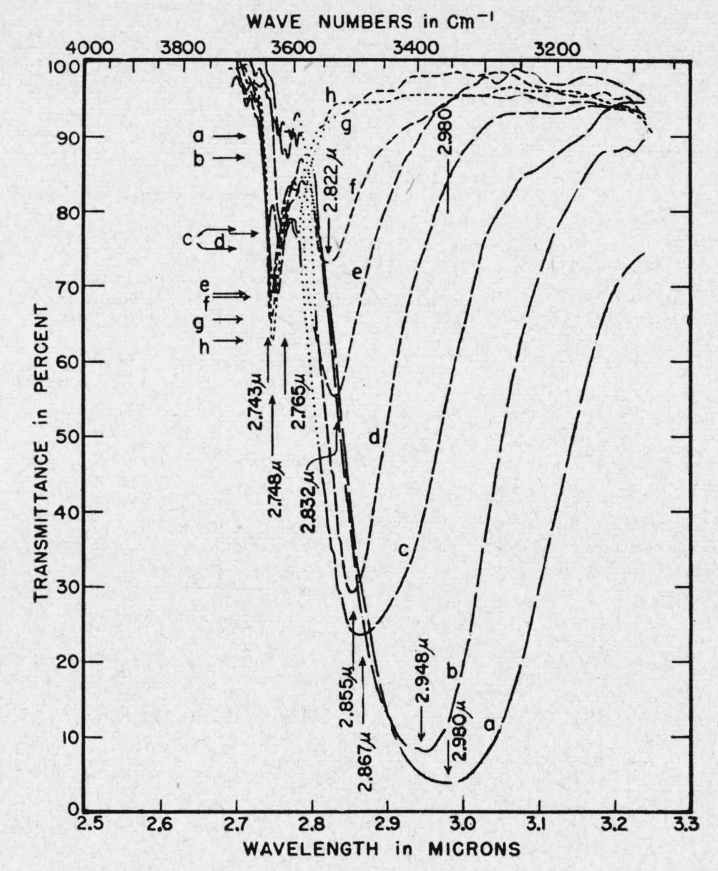

FiguRE 11. $\mathrm{O}-\mathrm{H}$ stretching fundamental showing progressively decreased association resulting from increased branching of alkyl derivatives of 3-pentanol.

Curve (a) 3-pentanol; (b) 3-methyl-3-pentanol; (c) 2,2,4-trimethyl-3-pentanol; (d) 2,4-dimethyl-3-ethyl-3-pentanol, (e) 2,2,4-trimethyl-3-ethyl-3-pentanol; (f) 2,2,4-trimethyl-3-isopropyl-3-pentanol; (g) 2,2,4,4-tetramethyl-3- $n$-propyl-3pentanol; (h) 2,2,4,4-tetramethyl-3-isopropyl-3-pentanol.
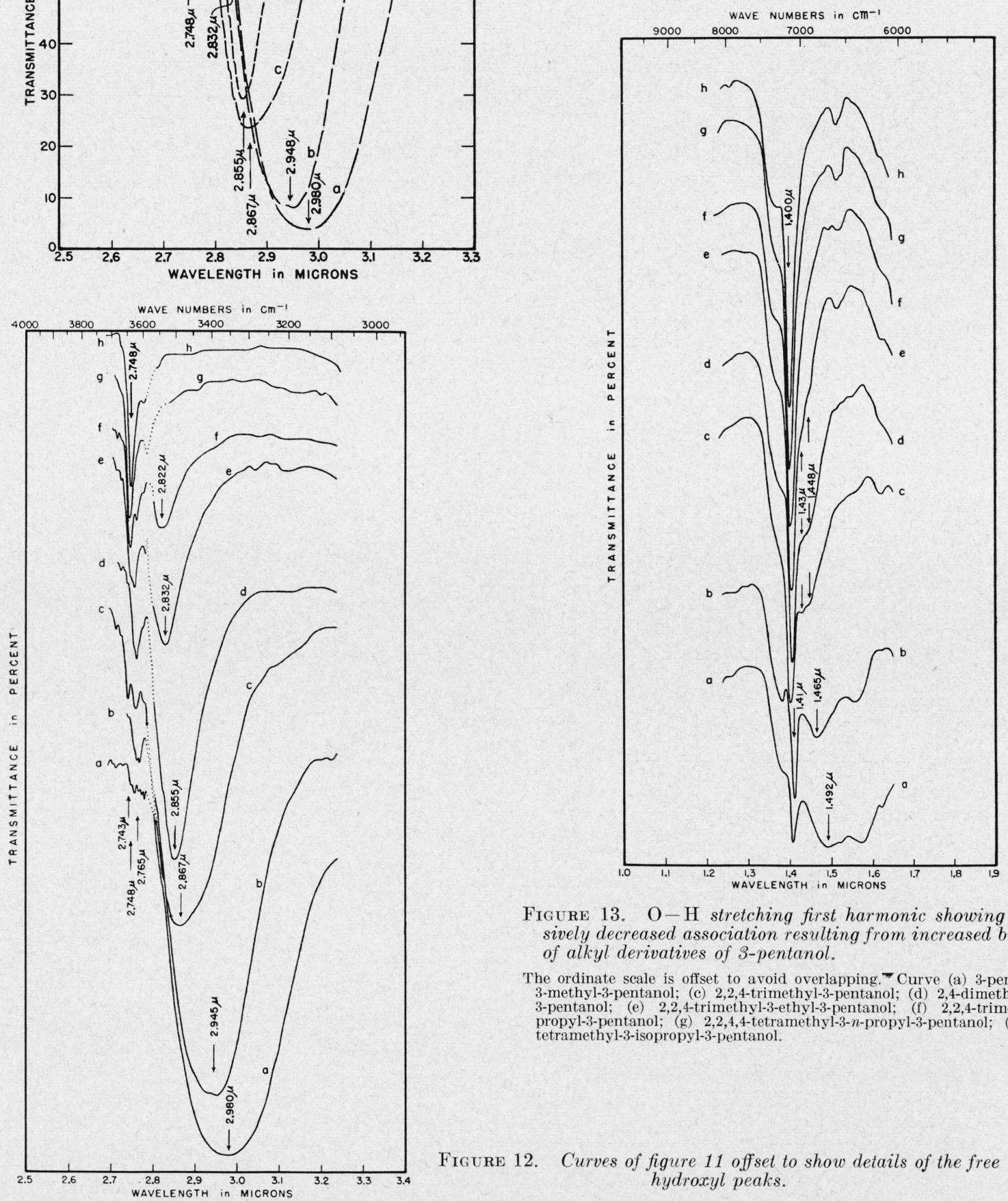

FIGURE 13. $\mathrm{O}-\mathrm{H}$ stretching first harmonic showing progressively decreased association resulting from increased branching of alkyl derivatives of 3-pentanol.

The ordinate scale is offset to avoid overlapping. - Curve (a) 3-pentanol; (b) 3-methyl-3-pentanol; (c) 2,2,4-trimethyl-3-pentanol; (d) 2,4-dimethyl-3-ethyl3-pentanol; (e) 2,2,4-trimethyl-3-ethyl-3-pentanol; (f) 2,2,4-trimethyl-3-isopropyl-3-pentanol; (g) 2,2,4,4-tetramethyl-3- $n$-propyl-3-pentanol; (h) 2,2,4,4. tetramethyl-3-isopropyl-3-pentanol.

Figure 12. Curves of figure 11 offset to show details of the free hydroxyl peaks. 
be somewhat uncertain. Bands in the vicinity of 6.2 and $9.4 \mu$ have been assigned by others to $\mathrm{O}-\mathrm{H}$ vibrations. It was hoped that changes in any bands of these alcohols in this range that accompanied dilution would serve to identify them as $\mathrm{O}-\mathrm{H}$ bands.

Figure 8 presents the spectrum of 3-pentanol from 6.65 to $9.70 \mu$, where preliminary trials indicated such changes. The band at $6.84 \mu(1,462$ $\mathrm{cm}^{-1}$ ) was used as the internal standard. The solid line represents the undiluted, or associated, alcohol and the dotted curve the most dilute solution $(0.1408$ moles/liter). Dashes of intermediate lengths indicate intermediate concentrations listed in the caption. One good isosbestic point appears at $8.82 \mu$ $\left(1,134 \mathrm{~cm}^{-1}\right)$ with a molar absorbancy index of 28.6. There are several other indications of possible isosbestic points. The location of such points in the spectra of compounds that dissociate on dilution may be of assistance in such analytical situations as those discussed by Coggeshall [16]. The differences in molar absorbancy index between the undiluted alcohol and the most dilute solution have been plotted in the upper part of figure 8. The solid curves indicate bands resulting from the associated molecules, and the dotted curves indicate those resulting from molecules most of which are monomeric as indicated by the small residual absorptions at 2.95 and $2.85 \mu$ of curve $d$ of figure 5 . The large number of bands in this region affected by dilution may be the result of perturbations of the $\mathrm{O}-\mathrm{H}$ bending by the terminal methyl groups of 3-pentanol, which can, and possibly do, come very close to the hydroxyl when the whole molecule is flexed.

It was expected that this situation could be prevented and the result simplified by the use of a simpler molecule. Figure 9 presents the spectrum of methanol from 2.5 to $12 \mu$ obtained with a rocksalt prism. The band at $3.39 \mu$ was used as the internal standard. The solid curve represents the undiluted alcohol, almost completely associated, as indicated by the small absorption at $2.74 \mu$. The dotted curve represents a dilute solution $(0.0478$ moles/liter) in which the molecules are essentially monomeric, as indicated by the small absorptions at 2.96 and $2.84 \mu$. The dashed curve represents an intermediate concentration. Carbon tetrachloride and carbon disulfide were used as solvents. The gaps between 4.16 and $4.80 \mu$ and between 6.16 and $6.68 \mu$ in the curves for the solutions result from the opacity of both solvents in this region. Differences in molar absorbancy index between the undiluted alcohol and the dilute solution are shown in the upper part of the figure. The solid difference curves represent peaks resulting from associated molecules, and the dotted curves indicate those resulting from molecules most of which are monomeric.

The strong band at $9.70 \mu\left(1,031 \mathrm{~cm}^{-1}\right)$, ascribed by Borden and Barker [17] and by Davies [6] to the $\mathrm{C}-\mathrm{O}$ stretching vibration between the methyl and hydroxyl groups, moves from $9.70 \mu$ in the undiluted alcohol to $9.78 \mu$ and greater intensity at 0.108 molar in carbon disulfide. At an intermediate concentration the band appears at an intermediate wavelength and intensity. The change in wavelength from undiluted alcohol to 0.108 molar is the same $(0.08 \mu)$ as that reported by Davies for his solutions in chloroform.

A slight shoulder appears on the short-wavelength side of the peaks of both solid and dotted curves, which may be caused by the inplane deformation vibration that Borden and Barker predicted, but did not find, for monometer at $9.71 \mu$. The shoulder appears here in the dotted curve at $9.74 \mu$, and in the undiluted alcohol at $9.67 \mu$.

Instead of the weak absorption reported by Davies at $\left.9.31 \mu,(1,074) \mathrm{cm}^{-1}\right)$ an unequal doublet appears with components at $9.27\left(1,079 \mathrm{~cm}^{-1}\right)$ and $9.35 \mu$ $\left(1,070 \mathrm{~cm}^{-1}\right)$. The latter, which is stronger, corresponds exactly in wavelength with the "difference tone" between the two fundamentals $\left(1,340 \mathrm{~cm}^{-1}-\right.$ $270 \mathrm{~cm}^{-1}=1,070 \mathrm{~cm}^{-1}$, or $9.35 \mu$ ) mentioned by Davies in this connection. Both appear to be connected with free hydroxyl.

Instead of the weak band at $9.01 \mu$, ascribed by Davies to the in-plane deformation vibration of $\mathrm{O}-\mathrm{H}$ in associated molecules, we find an absorption connected with polymer at $8.94 \mu$. Davies states, however, that this absorption moves to $8.96 \mu$ at 7.90 molar in chloroform.

One of the fundamental vibrations ( $\nu_{6}$ of Borden and Barker, at $7.47 \mu\left(1,339 \mathrm{~cm}^{-1}\right)$ was found by Davies as a single sharp peak at $7.52 \mu$. Borden and Barker attributed this to the $\mathrm{C}-\mathrm{O}$ bending vibration, resolvable into two mutually perpendicular components one in and one out of the $\mathrm{C} \mathrm{O} \mathrm{H}$ plane and predicted a close doublet. The doublet, however, was unresolved by them in vapor or by Davies in dilute chloroform solution. This absorption appears in figure 9 as a close unresolved doublet with the stronger component at $7.52 \mu,\left(1,330 \mathrm{~cm}^{-1}\right)$ where Davies found a single peak, and the weaker at the $7.47 \mu,\left(1,339 \mathrm{~cm}^{-1}\right)$ predicted by Borden and Barker for the other component of the doublet.

Although Davies makes a good case for the assignment of this band to $\mathrm{C}-\mathrm{O}$ bending, its wavelength falls in the general range of free $\mathrm{O}-\mathrm{H}$ bending vibrations. This is too short a wavelength to be compatible with a $\mathrm{C}-\mathrm{OH}$ bending vibration unless the hydroxyl is associated. Figure 9 shows that the band increases in intensity on dilution, which connects it with a free vibration rather than an associated one, as did its presence in the vapor of Borden and Barker and the dilute solution of Davies. Its assignment by them to a fundamental $\mathrm{C}-\mathrm{O}$ bending vibration therefore seems highly questionable, especially since they have assigned the strong band at $9.70 \mu$ to $\mathrm{C}-\mathrm{O}$ stretching.

The band reported by Davies at $7.14 \mu(1,401$ $\mathrm{cm}^{-1}$ ), and attributed by him to the counterpart for polymer of the $7.52 \mu\left(1,330 \mathrm{~cm}^{-1}\right)$ monomer band, appears in figure 9 at $7.04 \mu\left(1,420 \mathrm{~cm}^{-1}\right)$.

Two $\mathrm{C}-\mathrm{H}$ bending fundamentals $\left(\nu_{4}\right.$ and $\nu_{3}$ of Borden and Barker at 6.77 and $6.87 \mu$ in vapor) appear in figure 9 at 6.77 and $6.89 \mu$, but seem to be affected by dilution, which should not be the case unless they represent additional contributions to a 
broad polymer absorption that overlaps their wavelengths.

The validity of the small difference peaks between 3.6 and $6.3 \mu$ is in some doubt, because of the extremely small absorptions from which they are derived and because the dashed curve for the intermediate concentration does not in general fall between the other two. However, the monomer peak at $4.92 \mu\left(2,033 \mathrm{~cm}^{-1}\right)$ and the polymer peak at $4.86 \mu$ $\left(2,058 \mathrm{~cm}^{-1}\right)$ are the first harmonics of the intense bands at $9.7 \mu$, and they bear the same relation to the intense bands in both wavelengths and intensity. Furthermore, the curve representing the intermediate concentration appears between the other two in both cases.

The peak at $10.17 \mu$ in figure 9 was observed in the carbon tetrachloride solution but not in carbon disulfide. It has not so far been accounted for, but it appears to be connected with monomer.

The spectrum of liquid methanol from 2 to $15 \mu$ obtained with a rock-salt prism and several cells is presented in figure 10. The solid curve of figure 9 was plotted on its linear ordinate scale (molar absorbance index) from the same data from which two of the curves of figure 10 were plotted. In the latter, the ordinate scale (transmittance in percentage) is logarithimic in absorbance. Each type of plot emphasises and facilitates the presentation of spectral information that the other cannot.

\section{Effect of Steric Hindrance on Association}

Several workers, notably Coggeshall [15] and Sears and Kitchen [18] have shown that steric hindrance affects the intra- and intermolecular formation of hydrogen bridges in phenols. The effect of progressive branching on the association of a series of alkyl derivatives of 3-pentanol is shown in figures 11,12 , and 13 . Figures 11 and 12 present the effect on the $\mathrm{O}-\mathrm{H}$ stretching fundamental, and figure 13 shows the effect on its first harmonic. Figure 12 presents the curves of figure 11 with the intensity scale offset to avoid obscuring details of the bands of free hydroxyl. The curves are lettered from (a) to $(\mathrm{h})$ in the order of increasing branching. It is seen that the progressive effect on association is in the same order.

In the light of the information developed in the dilution experiments with individual alcohols, the following interpretation of figure 11 is offered. In the alcohols represented by curves a, b, c, and d, monomer, dimer, and polymer coexist in differing relative proportions. Considering them in turn from a to $\mathrm{d}$, the polymer absorption at 2.98 progressively decreases, with a corresponding increase in dimer absorption at 2.855 , which reaches a maximum in $c$ and decreases again in $d$. This gives rise to the apparent progressive shift of the center of the band to successively shorter wavelengths. Curve a is symmetrical. Curve b indicates a predominance of polymer with a slight bulge on the short wavelength side, indicating an increasing contribution of dimer to the absorption. Curve $\mathrm{c}$ indicates a predominance of dimer with a bulge on the long wave- length side, indicating the residual contribution of polymer to the absorption. Curve $d$, which is again approximately symmetrical, indicates that although the dimer population is less than in c, the polymer population has almost disappeared, as shown by the small absorption at $2.98 \mu$. Simultaneously with these changes the population of free hydroxyl has progressively increased, as may be seen more readily in figure 12 .

Considering curves $\mathrm{d}$, e, f, g, and h, as more and more methyl groups are substituted for the hydrogen atoms on the chain, the mutual repulsion of the mass of hydrogen atoms of one molecule for those of another prevents as close an approach of the hydroxyl groups as had been possible before. Not only does the formation of polymer become impossible, but the hydrogen bridge to form dimer is progressively stretched out. The progressively weakened bridge in dimer exerts less and less effect upon the $\mathrm{O}-\mathrm{H}$ valence bond, with the result that the force constant of the latter is greater and the wavelength of its vibration is progressively shorter until in $f$ it appears at $2.822 \mu$. In curve $\mathrm{g}$ the dimer population has decreased until the absorption is a mere vestige, which has disappeared in h. Simultaneously the population of free hydroxyl has continued to increase, as may be seen from both figures 11 and 12 .

The free hydroxyl band of curve $c$ in figure 11 is a doublet with the stronger peak at $2.765 \mu$ and the weaker at $2.743 \mu$. It will be noted that as branching increases from curve a to curve $h$ the more intense absorption in the free hydroxyl band tends in general to shift from 2.765 to $2.748 \mu$.

In figure 12 it will be seen more readily that the free hydroxyl peaks of curves a and $b$ occur in the vicinity of $2.76 \mu$. The doublet of curve c occurs at about 2.76 and $2.74 \mu$, and those of curves $d$ and $e$ occur at about $2.76 \mu$ with shoulders on the shortwavelength sides. In curves $f, g$, and $h$ the free hydroxyl peak occurs at $2.748 \mu$, in curve $f$ with a spur, and in curve $\mathrm{g}$ with a shoulder, on the longwavelength side. These data support those presented above in connection with the dilution study of 2,4-dimethyl-3-ethyl-3-pentanol, illustrated in figure 6 , and are strongly indicative of the existence of a single-bridge type of dimer. Of course the singlebridge type of linkage between molecules lends itself to the formation of polymeric aggregates by the addition of more molecules to dimer, as in figure 1 . Unless these aggregates form closed rings, there would always be one free $\mathrm{O}-\mathrm{H}$ per aggregate of polymer, which would contribute its absorption at so nearly the same wavelength as the free hydroxyl of dimer as to be indistinguishable from it. The relative contribution of such terminal hydroxyl groups would of course decrease as the size of the aggregate increased. In the less branched molecules polymer would predominate, and the free hydroxyl absorption of curves a and $b$ of figure 12 would be accounted for by relatively few dimeric pairs linked by a single bridge. Then as branching increases, dimer would predominate, with some monomer as indicated by the shoulders on the short wavelength sides of the 
peaks of curves $d$ and e. On further branching the remaining dimer would dissociate until finally almost all the free hydroxyl absorption would be from monomer, as indicated by curves $\mathrm{g}$ and $\mathrm{h}$ at $2.748 \mu$.

Several of the curves show minor peaks from 2.78 to $2.79 \mu$ that vary with the different alcohols. These may be artifacts or contributions of other vibrations in the molecule than those of $\mathrm{O}-\mathrm{H}$.

The free hydroxyl absorption, as shown by the first harmonic in figure 13 , follows the same general pattern as that just described, occurring at wavelengths as long as $1.41 \mu$ in curves a and b and appearing consistently at $1.400 \mu$ in curves $\mathrm{f}, \mathrm{g}$, and $\mathrm{h}$. Small absorptions at $1.43 \mu$ in curves $c, d$, and e may be those of dimer. Those at $1.492 \mu$ in a and at $1.465 \mu$ in b probably represent polymer. The small shoulders at $1.448 \mu$ in curves $\mathrm{c}$, $\mathrm{d}$, and e have not been identified.

The absorptions from 1.37 to $1.38 \mu$ and those above 1.50 appear not to be connected with hydroxyl.

The spectra of the alkyl derivatives of 3-pentanol, successively branched by the substitution of methyl groups for hydrogen, as observed using the rock-salt prism, are shown in figures 14 to 21 , and as observed by using the lithium fluoride prism in figures 22 to 29. It will be seen in the latter group of figures that the first harmonic of the free hydroxyl vibration at about $1.4 \mu$ is always stronger, relative to the bands resulting from associated hydroxyl, than is the case with the fundamentals, as noted by Stanford and Gordy [19].

In connection with steric effects, it may be of interest to note the use of the difference in wavelength between monomer and polymer bands as a measure of the electronegativity of the group or atom to which the bridge-forming hydrogen is attached, such as in the studies by Gordy and others, of which the paper by Gordy and Stanford [20] is an example. Also to be noted is the use of the difference as a measure of steric hindrance in studies like those of Coggeshall [16] and Sears and Kitchen [18] with phenols. It would appear that such studies may be expected to yield valid results only where the effect of each factor is considered in the study of the other. The variations in size, and the effects on the distance of approach; of molecules produced by branching in the present study have negligible effect upon the electronegativity of the carbon atom to which the hydroxyl is attached. It is believed that observed differences in wavelength result predominantly from steric effects.

\section{Confirmation of the Assignment of the 2.86-Micron Band to Dimer}

It will have been noted that in the case of the $\mathrm{O}-\mathrm{H}$ stretching fundamental, the spectra of all the alcohols studied at concentrations intermediate between the undiluted alcohol and very dilute solutions show a band in the vicinity of $2.86 \mu$. This band also appears in carbohydrates such as sugars and cellulose. It has been ascribed to the dimer state of aggregation by several workers [3, 4], but at- tempts at proof have been indirect and not entirely conclusive. Direct methods have been unsuccessful because, invariably in solutions over a range of concentrations, monomer, dimer, and polymer states of aggregation coexist. The presence of polymerie aggregates, varying in the number of alcohol molecules per aggregate, and none of them known, made impossible for previous workers a direct solution for an equilibrium constant between monomer and dimer.

An examination of curve d of figure 11 in comparison with the other curves shows that 2,4-dimenthyl-3-ethyl-3-pentanol, undiluted, has a strong relatively sharp band at $2.855 \mu$ and only a relatively small absorption at $2.98 \mu$, indicating that this alcohol exists essentially as monomer and dimer. Any polymer present appears to be small relative to dimer and decreases on dilution, as shown in figure 6 .

2,4-Dimethyl-3-ethyl-3-pentanol (referred to hereinafter as the alcohol) was measured in successively more dilute solutions in carbon tetrachloride until the only significant absorption was that of free hydroxyl.

By plotting molar absorbancy index at $2.76 \mu$ versus the $\log$ of the concentration in formula weights per liter as in figure 30 and extrapolating to a constant value of the index, the working value of 44 was established for the molar absorbancy index of monomer.

Two assumptions were then made: (1) That the formula weight absorbancy index for the free hydroxyl of single-bridge dimer would be substantially the same as that for monomer; (2) that the absorptions of monomer at $2.76 \mu$ and dimer at $2.85 \mu$ separately would obey Beer's law. Then, using the value 44, (the molar absorbancy index of monomer), as a measure of free hydroxyl, the molar concentrations of total free hydroxyl in five solutions with total concentrations from 0.201 molar to the undiluted alcohol (5.92 molar) were determined.

On the basis of the evidence developed above for the existence of single-bridge dimer, values for the percentage of monomer in the mixture of monomer and single-bridge dimer contributing to the absorption of free hydroxyl were assumed in each of the six cases. This gave six values for the concentration of monomer, which, with the known total concentration, gave by difference six corresponding values for the concentration of the associated alcohol in formula weights per liter. From these and the measured absorptions at $2.86 \mu$, six values of the absorbancy index were obtained. Having assumed that this absorption obeys Beer's law, which implies that all six values of the formula weight absorbancy index should be the same, the values assumed above for the percentage of monomer in the mixture of monomer and single-bridge dimer were adjusted until the resulting six values of formula weight absorbancy index at $2.86 \mu$ were the same to \pm 0.5 percent. The assumed values of the percentage of monomer required to accomplish this result were plotted versus total concentration in figure 31. They were found to fall on a smooth curve and to be entirely reasonable.

The average value (61.42) for the formula weight 
absorbancy index for the remaining (associated) alcohol was then used with the cell thicknesses and measured absorptions at $2.86 \mu$ to compute six values for the concentrations of the remainder that did not differ significantly from those obtained by difference, but which had been smoothed slightly by adjusting and averaging the indices.

These formula weight concentrations of monomer and of the remainder as derived above were then used to compute the equilibrium constants $K_{1}=$ [remainder]/[monomer], $K_{2}=$ [remainder as dimer]/[monomer $]^{2}$, and $K_{3}=$ [remainder as trimer $] /[\text { monomer }]^{3}$.

The result is presented in the following table.

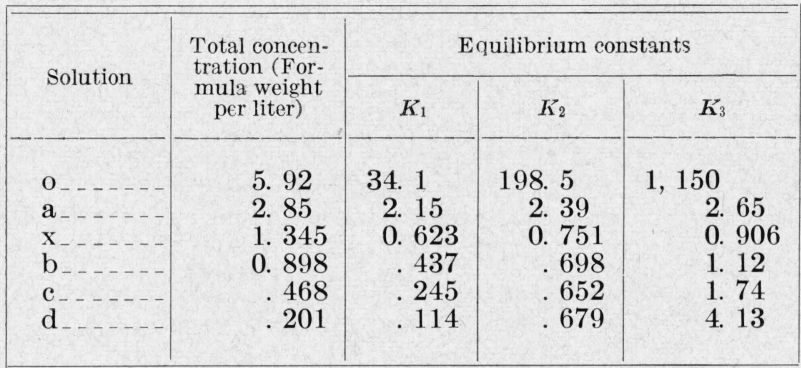

It will be noted that $K_{1}$ and $K_{3}$ show no indication of an approach to a constant value, whereas values of $K_{2}$ for total concentrations below about 1 molar are much more nearly constant than those of $K_{3}$. The fact that the values derived on the assumption of dimer are relatively constant for the lower concentrations tends to support the assignment of the absorption at $2.86 \mu$ to dimer. The increase in $K_{2}$ for solutions above about 1 molar indicates that monomer is decreasing faster than dimer is increasing. This probably means that above about 1 molar some polymer begins to form.

As an independent means of determining the state of aggregation, a method of isotonic vapor pressures similar in principle to that described by Lassettre and Dickinson [21] was chosen. Experiments of a preliminary nature were performed to determine the suitability of the method and to delineate the technique and control of variables that would be required for an accurate determination of the state of aggregation.

Solutions of orthoterphenyl and of alcohol of different concentrations in carbon tetrachloride were prepared by weight, placed in platinum cans with a large glass ball in each to insure mixing, the cans enclosed in a gold-plated brass bomb that was then evacuated and the assembly agitated during the approach toward equality of the vapor pressures of the two solutions. The formula weight absorbancy index of each solution at 2.76 and $2.86 \mu$ was determined before and after the experiment.

This, with the weights of the cans and contents before and after the experiment, permitted the computation of the final concentration of monomer and of the associated alcohol remaining as dimer or trimer, with one-half or one-third as many aggregates, respectively, as for monomer.

Had the uncertainties in the values of the several variables involved been sufficiently small, and had equilibrium been certainly attained, the final molar concentration of aggregates in the final alcohol solution should equal that in the final reference monomer solution. Compared with the molar concentration found by weighing for the reference monomer, the result favored dimer only slightly more than trimer, with monomer being definitely eliminated. Nevertheless, the results from this preliminary and inadequately controlled experiment tend to support those obtained by the other method. The information developed indicates that much more precise results may be expected under more accurately controlled experimental conditions.

The results of both methods lend support to the assignment of the $\mathrm{O}-\mathrm{H}$ stretching vibration at $2.86 \mu$ to dimer.

\section{Conclusions}

On the basis of information developed by others, as well as in the present study of progressively diluted alcohols, it is concluded that the use of the expression "wavelength shift" in connection with the difference in wavelength of absorption bands characteristic of monomer, dimer, and polymer states of aggregation may be misleading. It is suggested that this term be reserved for those cases in which the wavelength of a band changes progressively with changing conditions.

The effects of steric hindrance and of dilution upon the association of alcohols appear to be roughly parallel.

The location of suitable isosbestic points in the spectra of associated materials may facilitate the use of their spectra in quantitative analytical procedures.

The evidence for the existence of a single-bridge dimer appears to be as good as previous evidence against it, with the possibility that both singlebridge and double-bridge types may coexist.

The assignment to the dimeric state of aggregation of the band at $2.86 \mu$ has been given strong support by more direct methods, made possible by the use of 2,4-dimethyl-3-ethyl-3-pentanol. This assignment will facilitate the interpretation of the structure of carbohydrates by means of their spectra.

The consistent and reasonable results obtained by two independent methods used to confirm the dimer assignment lend confirmation to the assumptions upon which the computations were based: (a) That monomer and dimer separately obey Beer's law, (b) that a single-bridge type of dimer exists, and (c) that monomer and single-bridge dimer contribute to the free hydroxyl absorption in approximately the proportions assumed. 


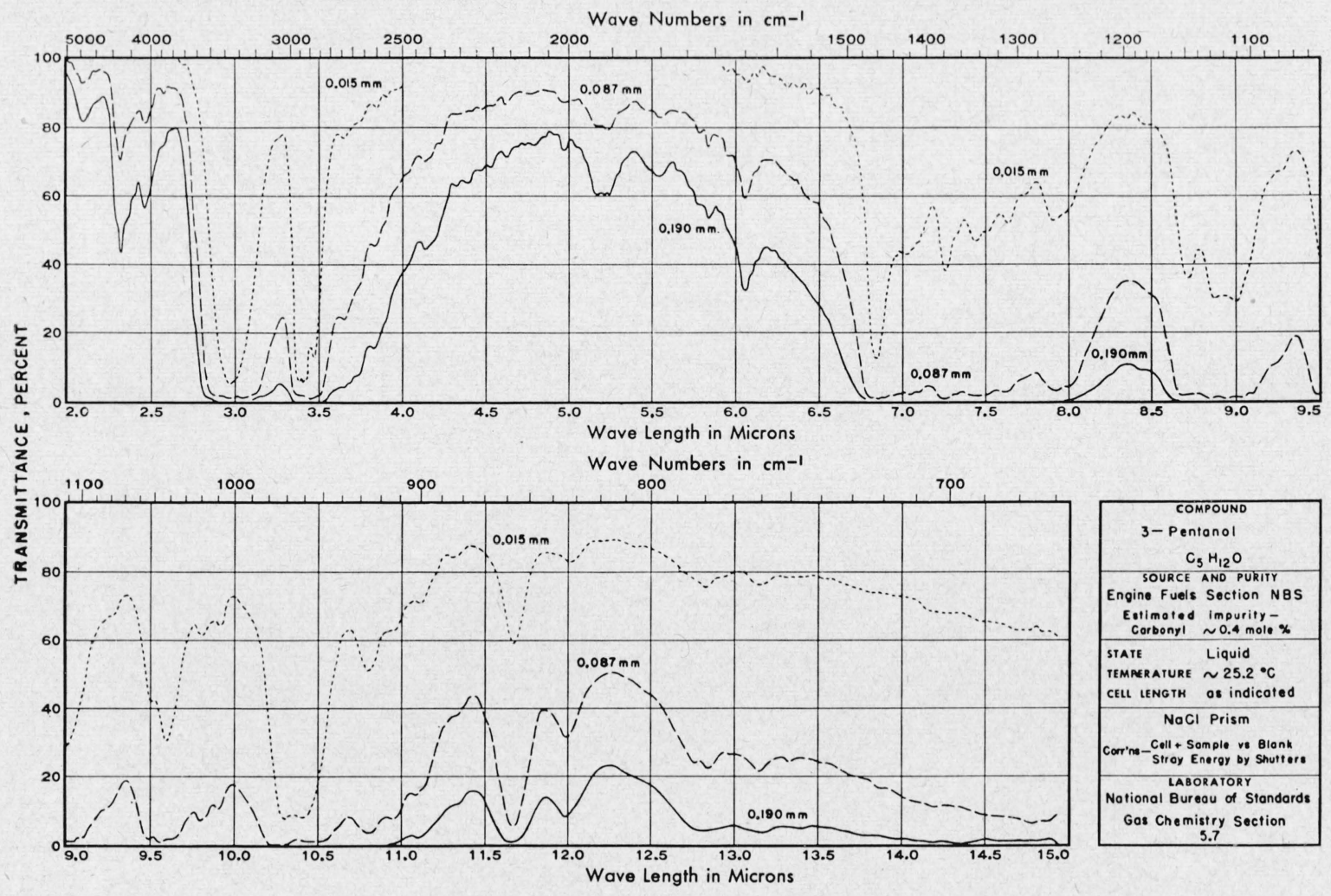

Figure 14. 3-Pentanol; $\mathrm{NaCl}$ prism.

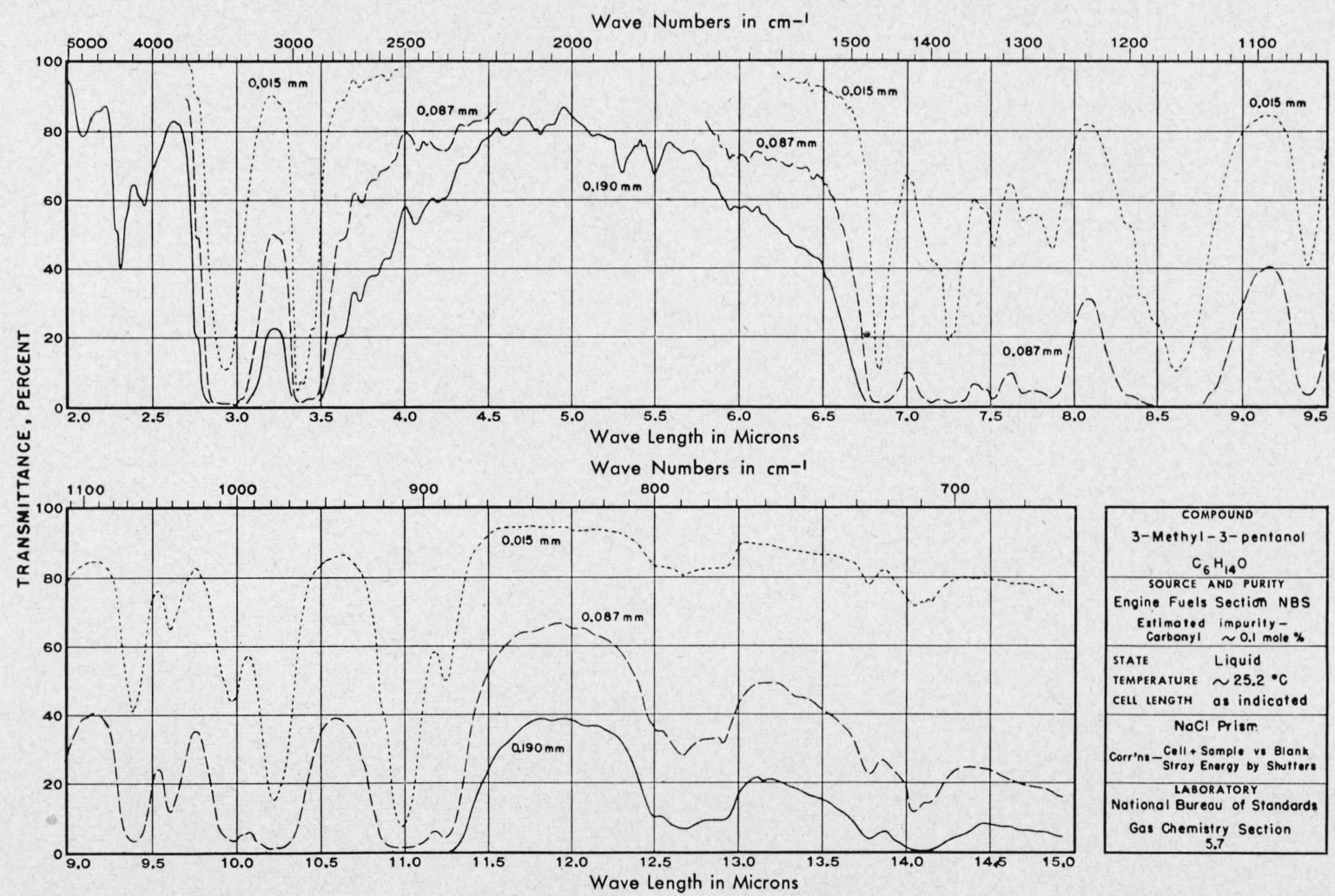

Figure 15. 3-Methyl-3-pentanol; $\mathrm{NaCl}$ prism. 


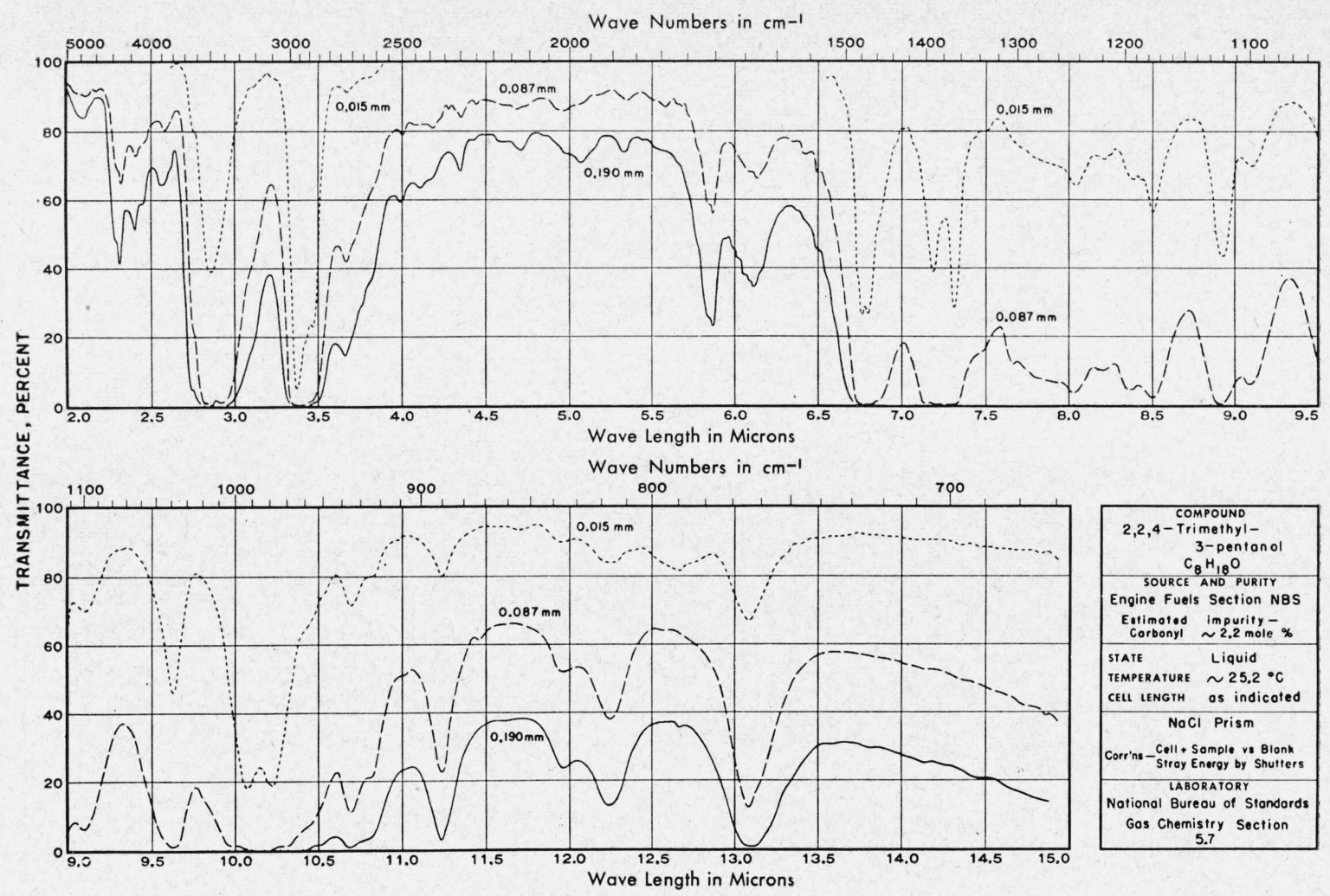

Figure 16. 2,2,4-Trimethyl-3-pentanol; $\mathrm{NaCl}$ prism.

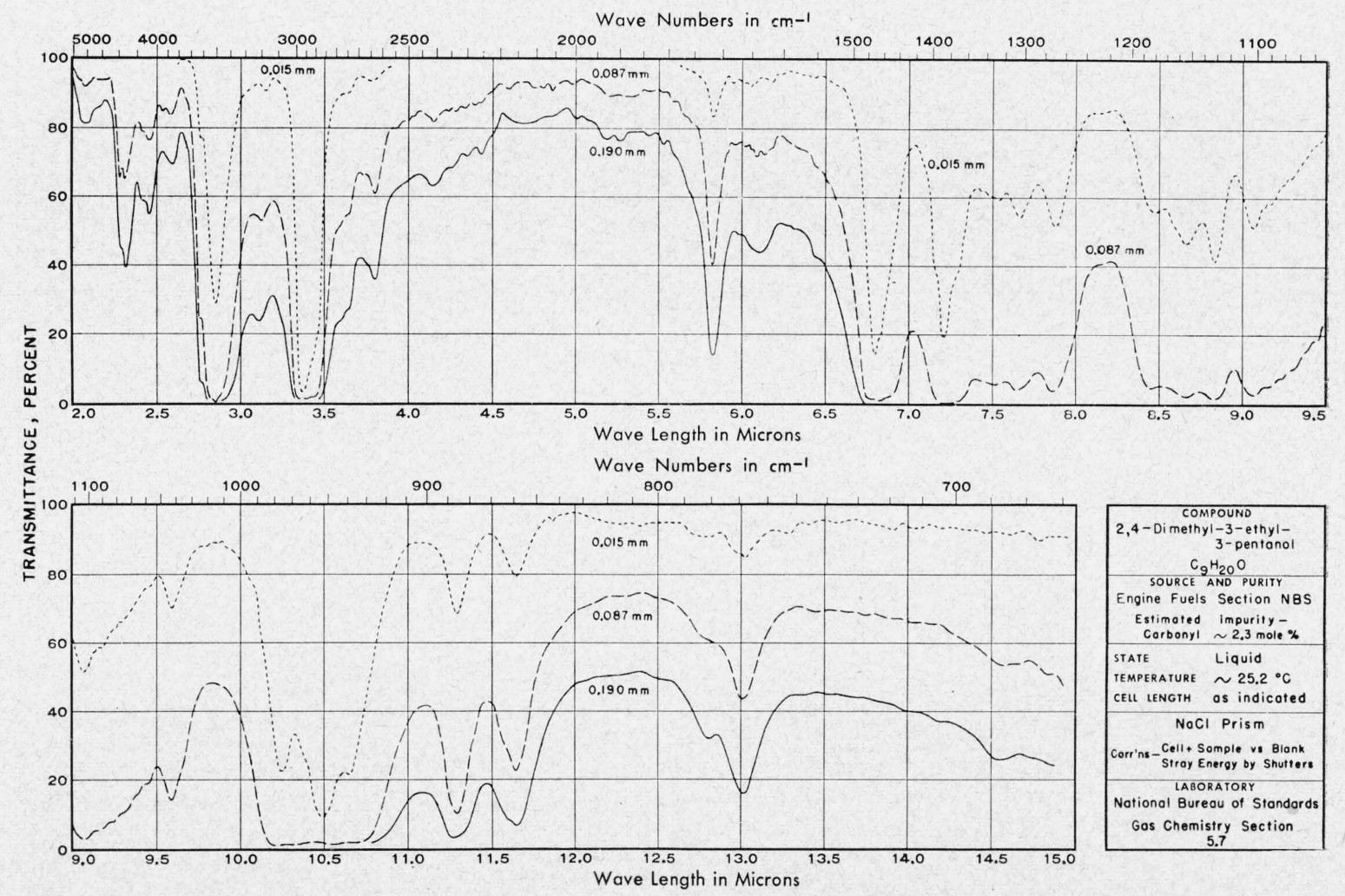

Figure 17. 2,4-Dimethyl-3-ethyl-3-pentanol; $\mathrm{NaCl}$ prism. 


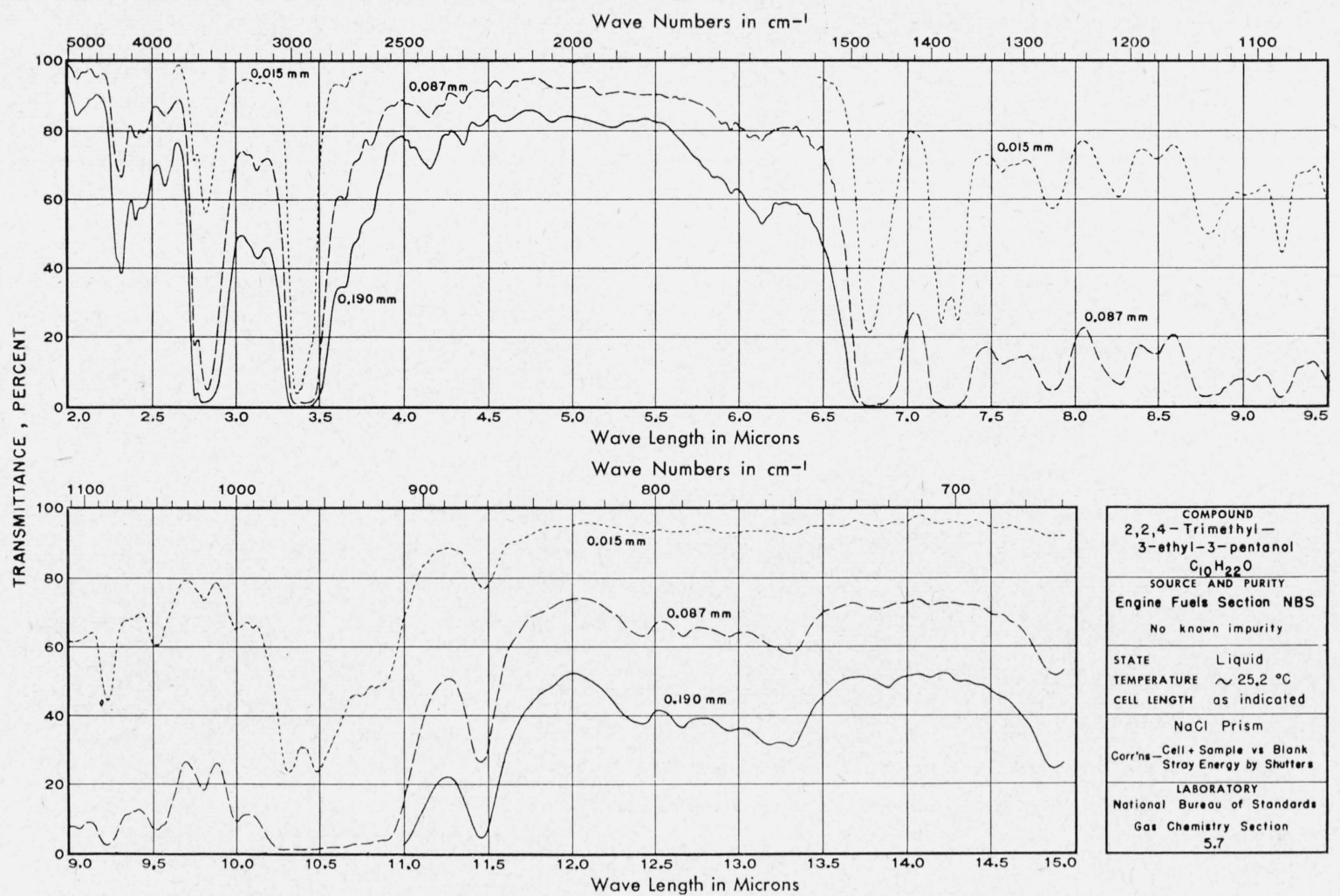

Figure 18. 2,2,4-Trimethyl-3-ethyl-3-pentanol; NaCl prism.

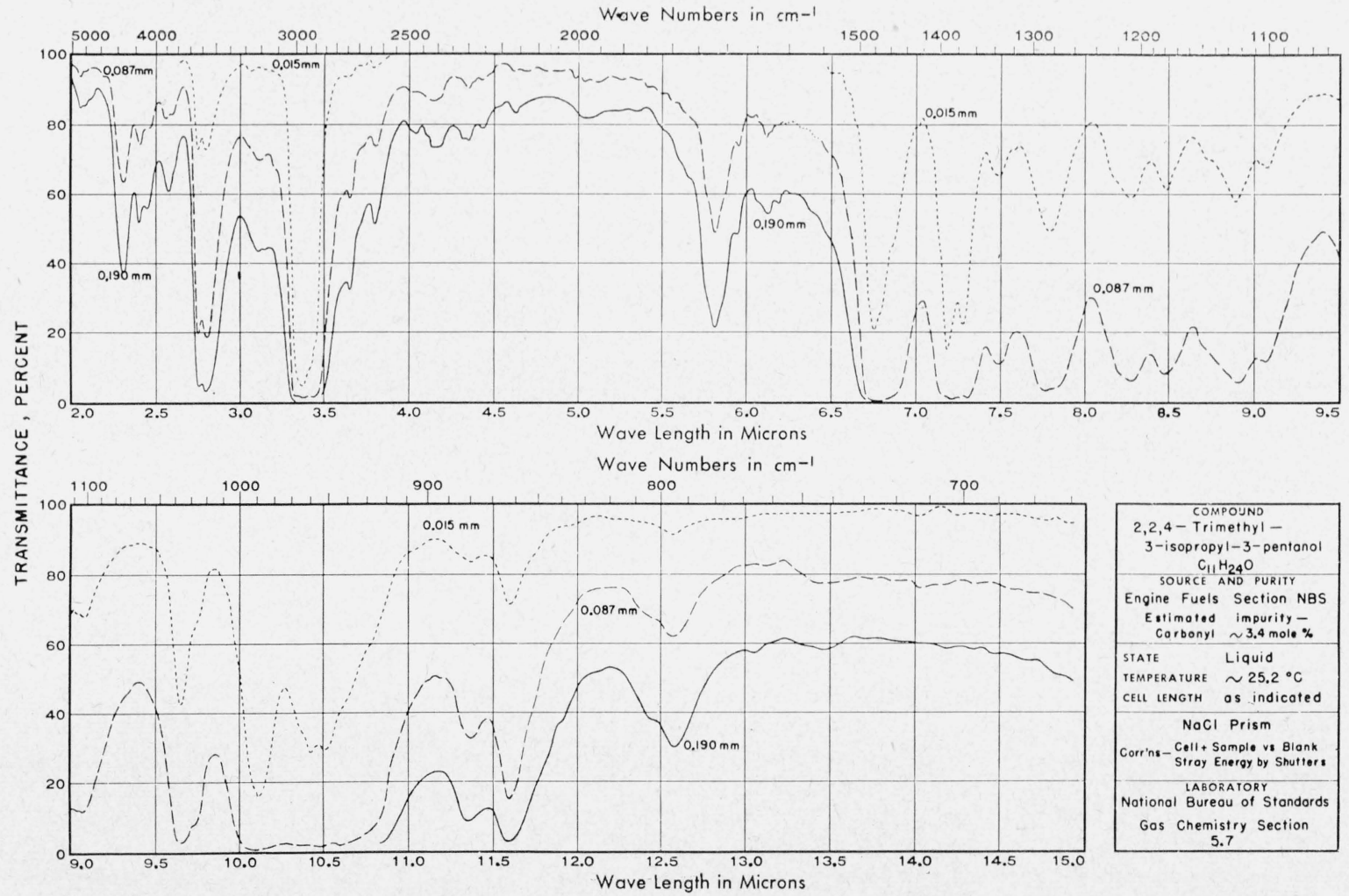

Figure 19. 2,2,4-Trimethyl-3-isopropyl-3-pentanol; $\mathrm{NaCl}$ prism. 


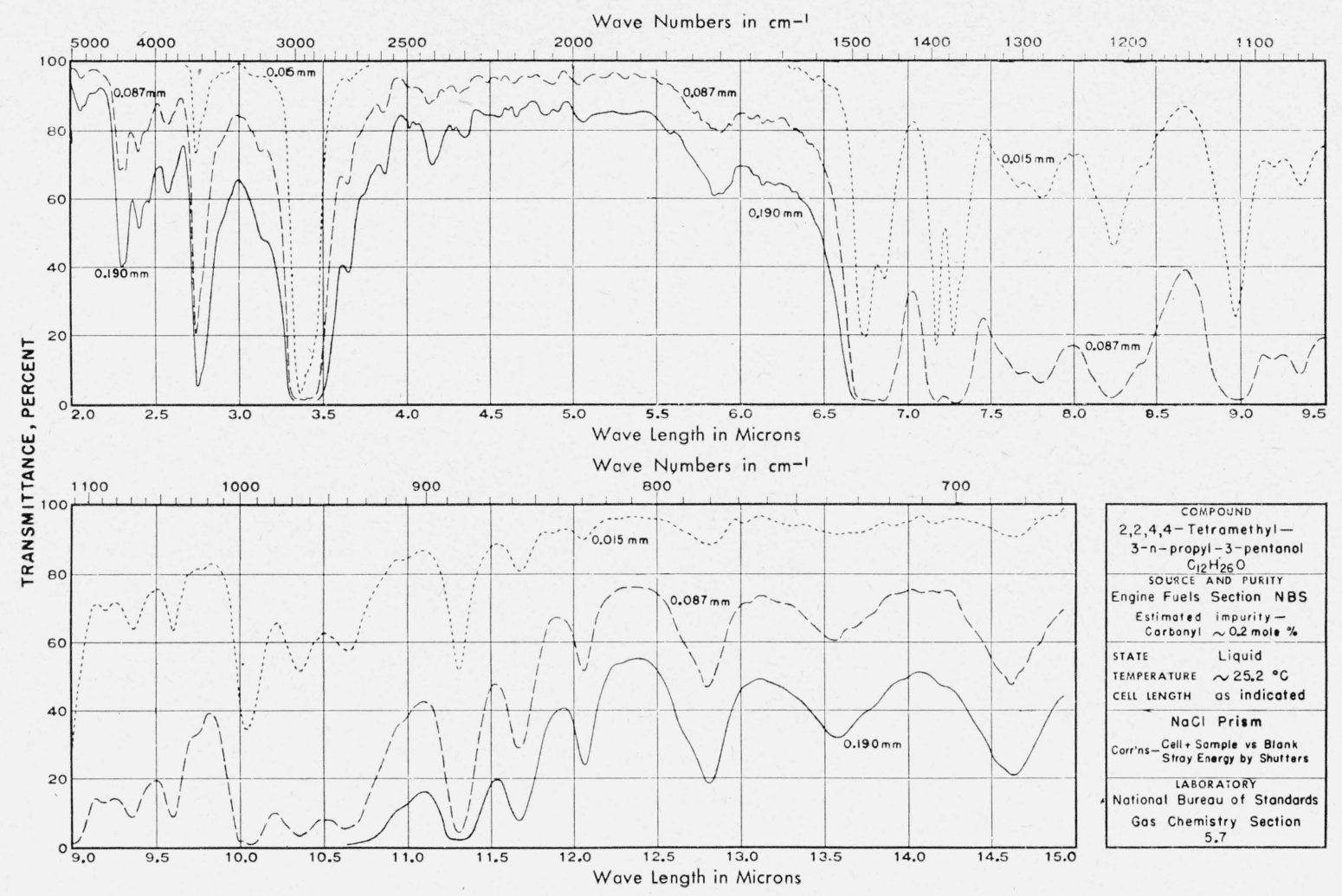

Figure 20. 2,2,4,4-Tetramethyl-3-n-propyl-3-pentanol; $\mathrm{NaCl}$ prism.

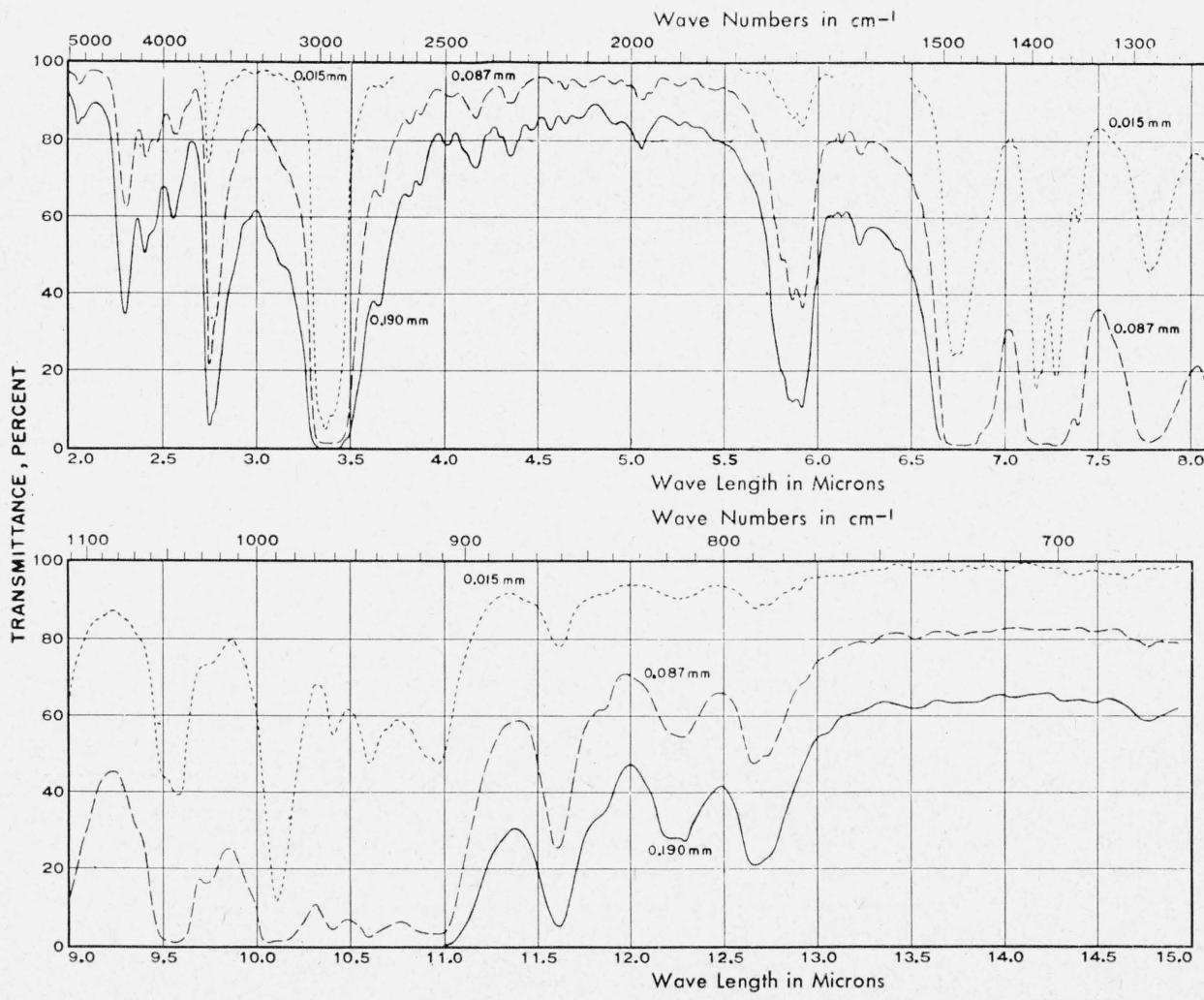

COMPOUN

$2,2,4,4$ - Tetromethyi3-isopropyl-3-pentanol $\mathrm{C}_{12} \mathrm{H}_{26} \mathrm{O}$
SOURCE

Engine Fue is Section NBS Engine Fue is Section NBS
Estimated impurityEstimated impurity-
Carbonyl $\sim 3.8$ mole \% state liquid TEMPERATURE $\sim 25.2^{\circ} \mathrm{C}$ CELL IENGTH OS indicated $\mathrm{NaCl}$ Prism

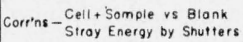
CLAORATORY National Bureau of Standards Gas Chemistry Section 5.7

Figure 21. 2,2,4,4-Tetramethyl-3-isopropyl-3-pentanol; $\mathrm{NaCl}$ prism. 


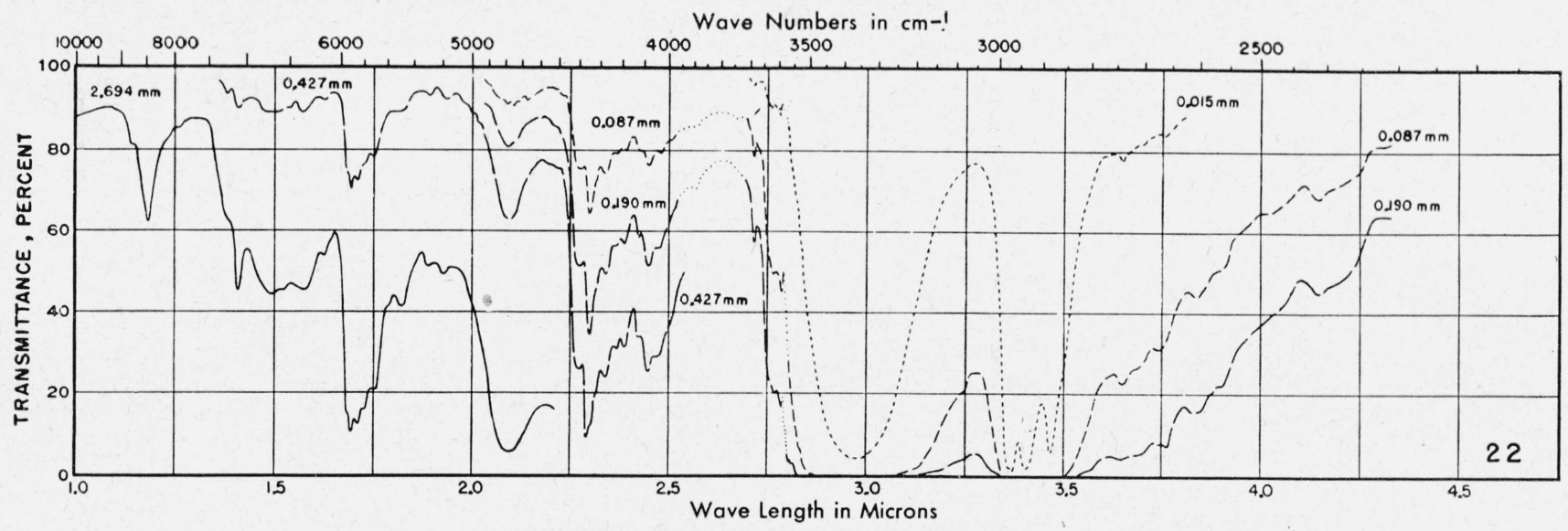

\begin{tabular}{|c|c|c|c|c|}
\hline $\begin{array}{r}\text { COMPOUNO } \\
\text { 3-Pentanol } \\
\mathrm{C}_{5} \mathrm{H}_{12} \mathrm{O}\end{array}$ & $\begin{array}{l}\text { SOURCE ARD PURITY } \\
\text { Engine Fuels Section NBS } \\
\text { Estimated impurity- } \\
\text { Carbonyl } \sim 0.4 \text { mole } \%\end{array}$ & $\begin{array}{l}\text { StATE } \\
\text { TEMPERATURE } \\
\text { CELL LeNGth }\end{array}$ & $\begin{array}{l}\text { Liquid } \\
\sim 25.2^{\circ} \mathrm{C} \\
\text { as indicated }\end{array}$ & $\begin{array}{c}\text { LiF Prism } \\
\text { Corr'ns- Celi+ Sompie vs Blank } \\
\text { Stray Energy by Shutters }\end{array}$ \\
\hline
\end{tabular}

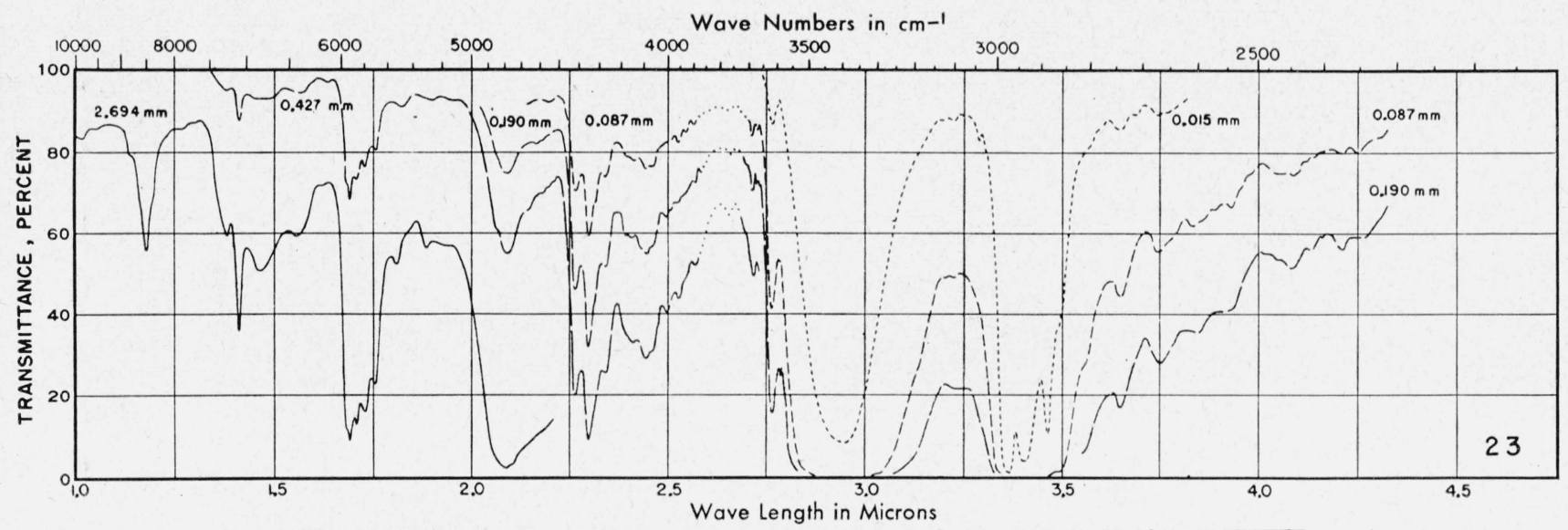

\begin{tabular}{|c|c|c|c|c|}
\hline $\begin{array}{c}\text { 3-Methyl-3-pentanol } \\
\mathrm{C}_{6} \mathrm{H}_{14} \mathrm{O}\end{array}$ & $\begin{array}{l}\text { SOURCE AND PURTYY } \\
\text { Engine Fuels Section NBS } \\
\text { Estimated impurity- } \\
\text { Corbonyl }\end{array}$ & $\begin{array}{l}\text { STATE } \\
\text { TEMPERATURE } \\
\text { CELL LENGTH }\end{array}$ & $\begin{array}{l}\text { Liquid } \\
\sim 25.2^{\circ} \mathrm{C} \\
\text { os indicated }\end{array}$ & $\begin{array}{c}\text { LiF Prism } \\
\text { Corr'ns-Cell + Somple vs Blank } \\
\text { Stray Energy by Shutters }\end{array}$ \\
\hline
\end{tabular}
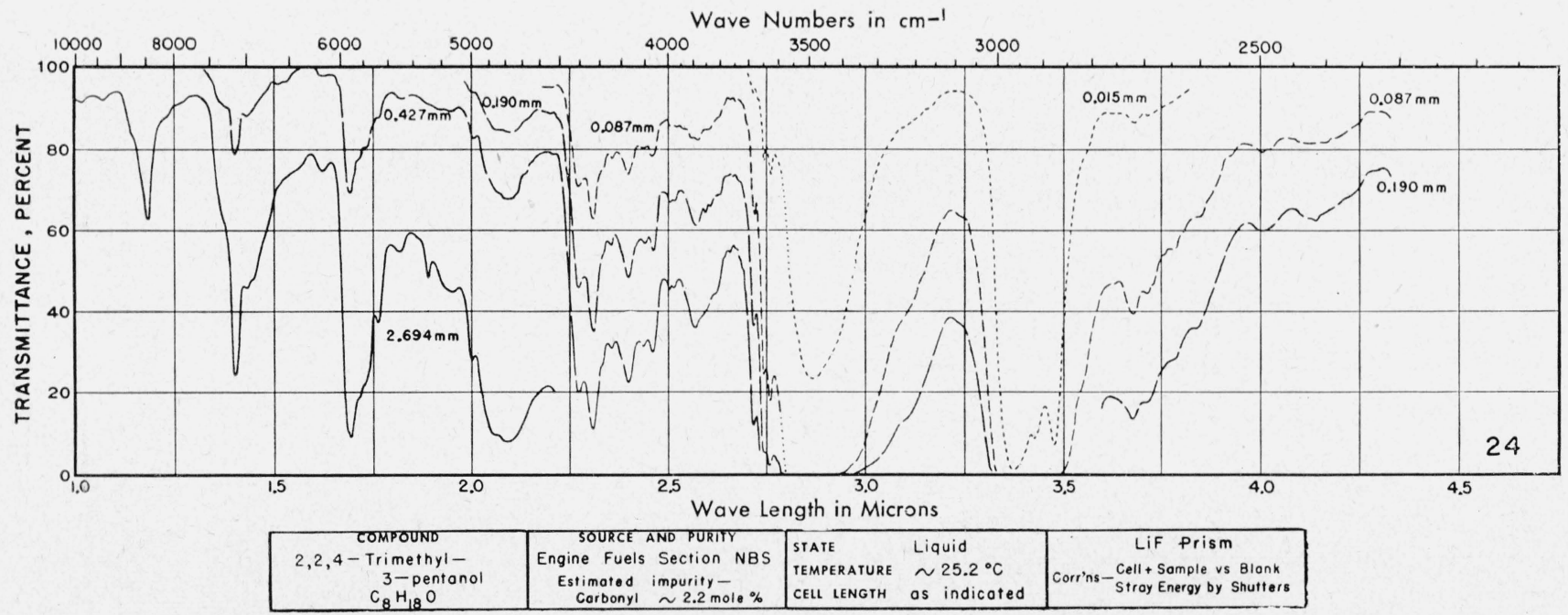

Figure 22. 3-Pentanol; LiF prism. Figure 23. 3-Methyl-3-pentanol; LiF prism.

Figure 24. 2,2,4-Trimethyl-3-pentanol; LiF prism. 

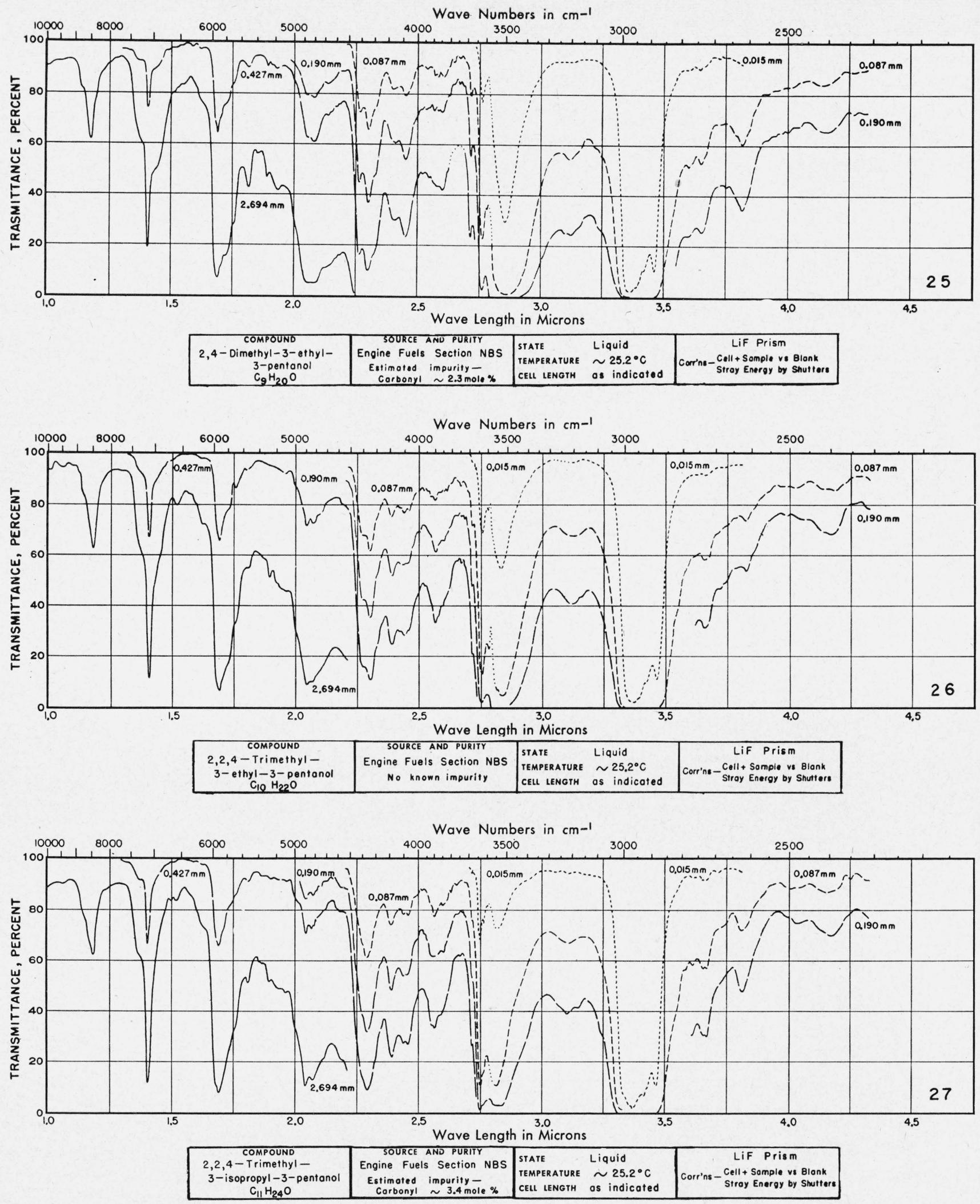

FiguRE 25. 2,4-Dimethyl-3-ethyl-3-pentanol; LiF prism. FigURe 26. 2,2,4-Trimethyl-3-ethyl-3-pentanol; LiF prism. FIGURE 27. 2,2,4-Trimethyl-3-isopropyl-3-pentanol; LiF prism. 


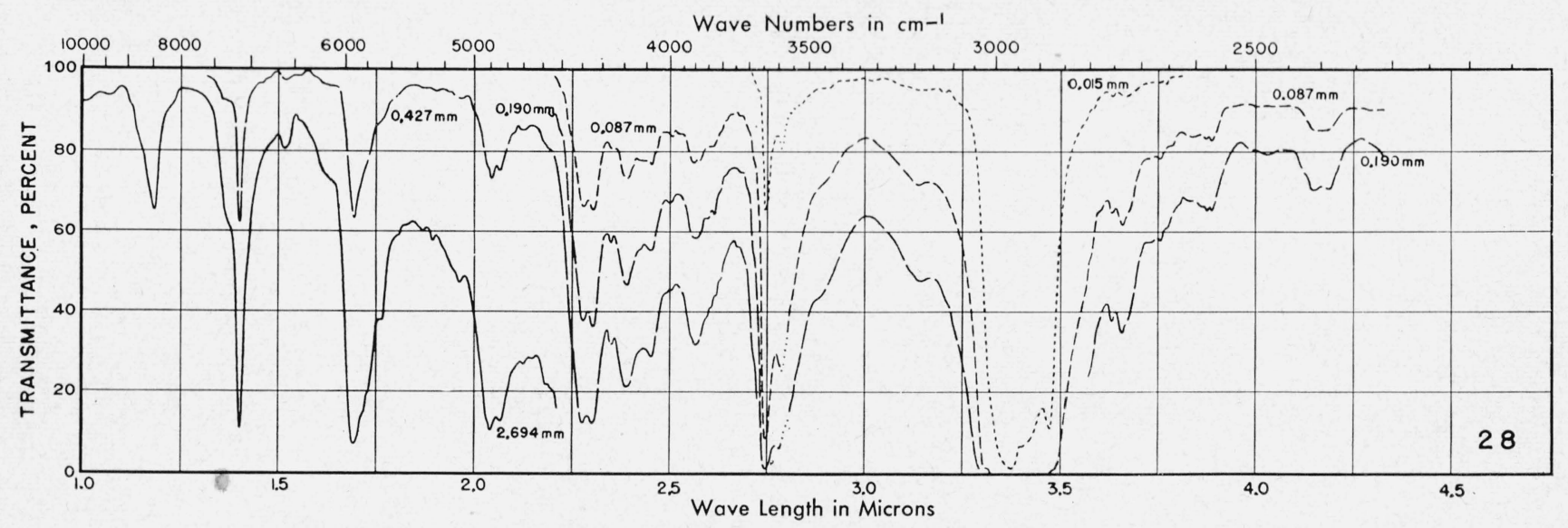

\begin{tabular}{|c|c|c|c|c|}
\hline $\begin{array}{l}\text { COMPOUND } \\
\text { 2,2,4,4-Tetramethyl- } \\
\text { 3-n-propyl-3-pentanol } \\
\mathrm{C}_{12} \mathrm{H}_{26} \mathrm{O}\end{array}$ & $\begin{array}{l}\text { SOURCE ARD PURTIY } \\
\text { Engine Fuels Section NBS } \\
\text { Estimated impurity- } \\
\text { Corbonyl } \sim 0.3 \mathrm{~mole} \%\end{array}$ & $\begin{array}{l}\text { STATE } \\
\text { TEMPERATURE } \\
\text { CELL LENGTH }\end{array}$ & $\begin{array}{l}\text { Liquid } \\
\sim 25.2^{\circ} \mathrm{C} \\
\text { as indicated }\end{array}$ & $\begin{array}{c}\text { LiF Prism } \\
\text { Corr'ns - Cell + Sample vs Blank } \\
\text { Stroy Energy by Shutters }\end{array}$ \\
\hline
\end{tabular}

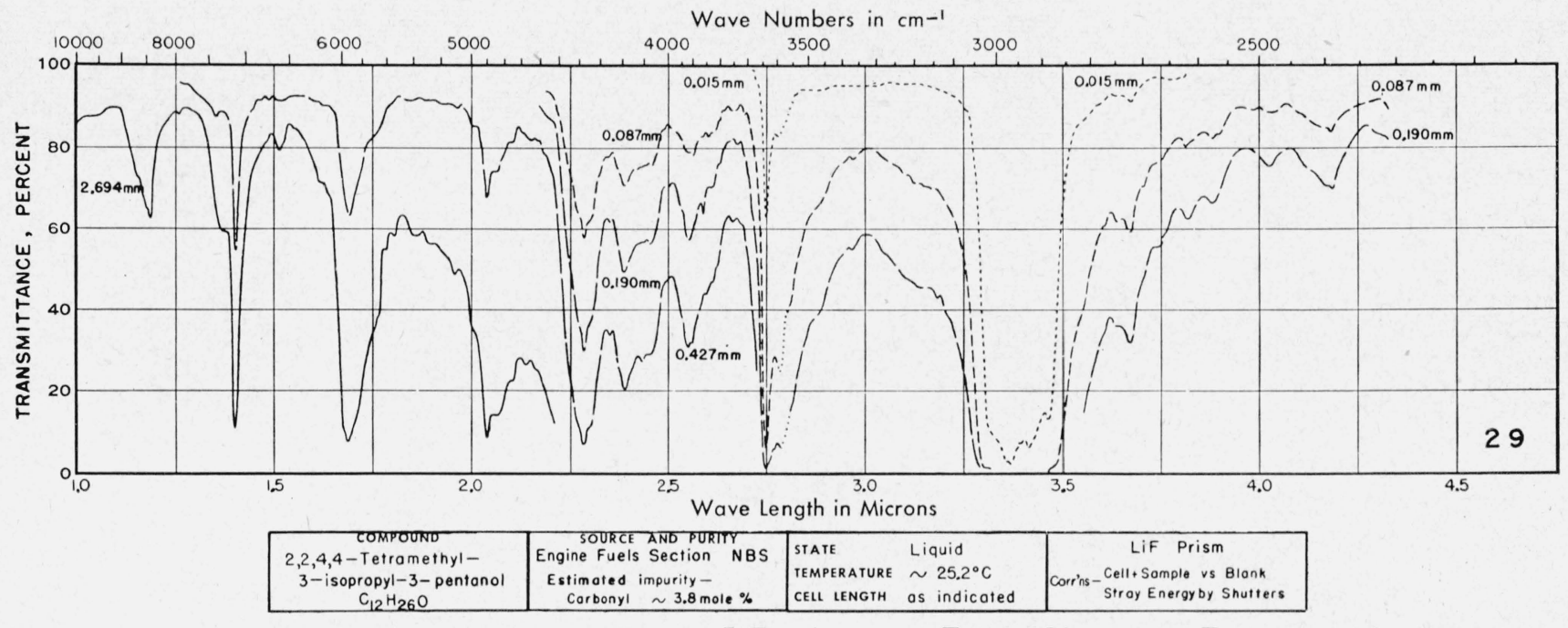

Figure 28. 2,2,4,4-Tetramethyl-3-n-propyl-3-pentanol; LiF prism. FIGURE 29. 2,2,4,4-Tetramethyl-3-isopropyl-3-pentanol; LiF prism.

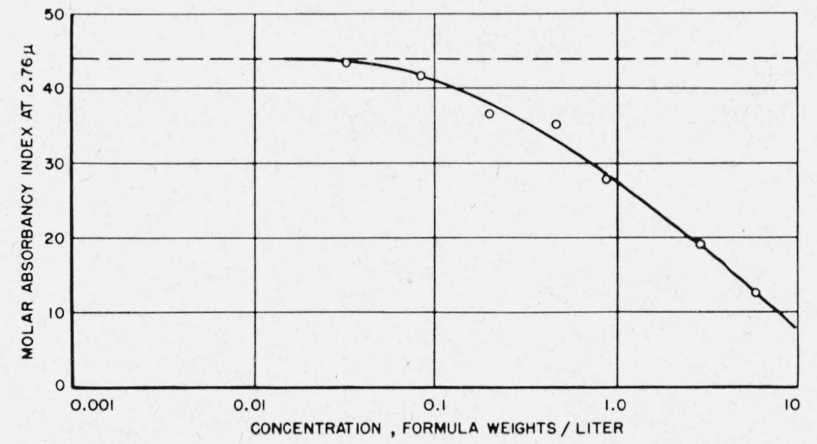

Figure 30. Molar absorbancy index for free hydroxyl (2.76 microns) versus concentration of 2,4-dimethyl-3-eihyl-3pentanol. 


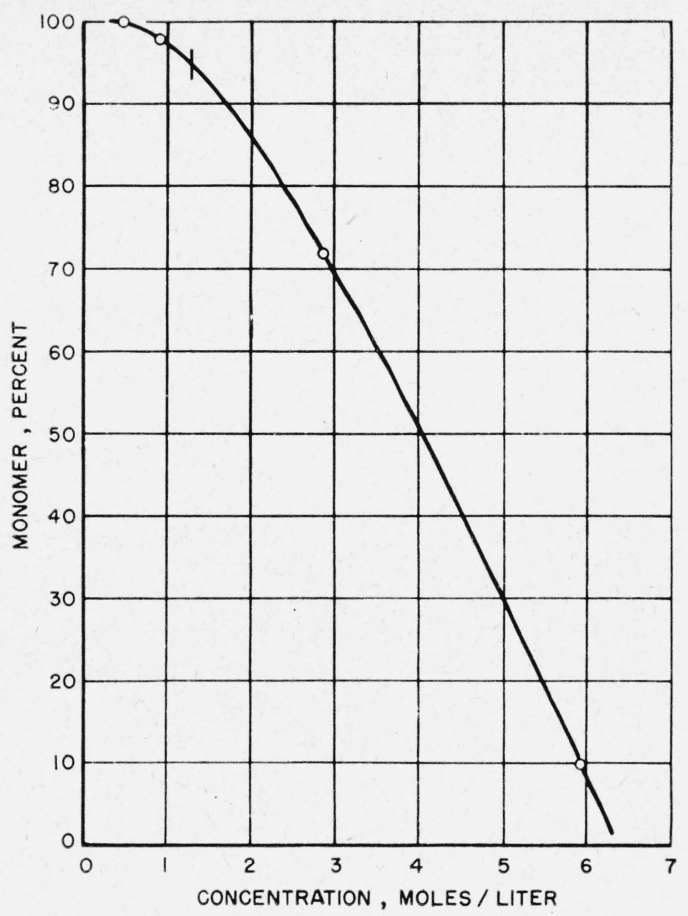

FiguRe 31. Percentage of monomer contributing to the free hydroayl absorption versus total molar concentration of 2,4dimethyl-8-ethyi-3-pentanol.

The authors express their appreciation to Frank L. Howard and Thomas W. Mears of the Engine Fuels Section of this Bureau for their cooperation in supplying the series of branched alkyl derivatives of 3-pentanol and data concerning their preparation and physical properties; to the Physical Chemistry 'Section for the use of the isotonic vapor pressure equipment; to Alan W. Smith, who assisted in the work with 2,4-dimethyl-3-ethyl-3-pentanol to prove the dimer assignment; and to John D. Hoffman, who supplied the 1-dodecanol.

\section{References}

[1] Maurice L. Huggins, J. Org. Chem. 1, 407 (1936).

[2] Linus Pauling, The nature of the chemical bond Chapter IX (Cornell Univ. Press, Ithaca, N. Y., 1939).

[3] J. J. Fox and A. E. Martin, Proc. Roy. Soc. (London) A162, 419 (1937).

[4] J. Errera, R. Gaspart, and H. S. Sack, J. Chem. Phys. 8, $63(1940)$.

[5] E. G. Hoffman, Z. physik. Chem. B53, 179 (1943).

[6] Mansel Davies, J. Chem. Phys. 16, 267 (1948).

[7] Norman D. Coggeshall, J. Chem. Phys. 18, 978 (1950).

[8] John D. Hoffman and Charles P. Smyth, J. Am. Chem. Soc. 71, 431 (1949)
[9] Edward A. Cadwallader, Abraham Fookson, Thomas W. Mears, and Frank L. Howard, J. Research NBS 41, 111 (1948) RP1909.

[10] E. Carroll Creitz and Francis A. Smith, J. Research NBS 43, 365 (1949) RP2031.

[11] Francis A. Smith and E. Carroll Creitz, Anal. Chem. 21, 1474 (1949).

[12] Don C. Smith and Elmer C. Miller, J. Optical Soe. Am. 34, 130 (1944).

[13] Eleanor L. Saier and Norman D. Coggeshall, Anal. Chem. 20, 812 (1948).

[14] J. J. Fox and A. E. Martin, Trans. Faraday Soc. 36, $897(1940)$

[15] Norman D. Coggeshall, J. Am. Chem. Soc. 69, 1620 (1947).

[16] Norman D. Coggeshall, Anal. Chem. 22, 381 (1950).

[17] A. Borden and E. F. Barker, J. Chem. Phys. 6, 553 (1938).

[18] William C. Sears and Leland J. Kitchen, J. Am. Chem. Soc. 71, 4110 (1949).

[19] S. C. Stanford and Walter Gordy, J. Am. Chem. Soc. 62, 1247 (1940).

[20] Walter Gordy and S. C. Stanford, J. Am. Chem. Soc. 62, 497 (1940).

[21] Edwin N. Lassettre and Roscoe G. Dickinson, J. Am. Chem. Soc. 61, 54 (1939).

Washington, October 13, 1950. 